Article

\title{
Computational Hybrid Machine Learning Based Prediction of Shear Capacity for Steel Fiber Reinforced Concrete Beams
}

\author{
Hai-Bang Ly ${ }^{1, *(\mathbb{D})}$, Tien-Thinh Le ${ }^{2, *(\mathbb{D})}$, Huong-Lan Thi Vu ${ }^{1}$, Van Quan Tran ${ }^{1}{ }^{\mathbb{C}}$, Lu Minh $\mathrm{Le}^{3}$ and \\ Binh Thai Pham 1,*(D) \\ 1 University of Transport Technology, Hanoi 100000, Vietnam; lanvth@utt.edu.vn (H.-L.T.V.); \\ quantv@utt.edu.vn (V.Q.T.) \\ 2 Institute of Research and Development, Duy Tan University, Da Nang 550000, Vietnam \\ 3 Faculty of Engineering, Vietnam National University of Agriculture, Gia Lam, Hanoi 100000, Vietnam; \\ lmlu@vnua.edu.vn \\ * Correspondence: banglh@utt.edu.vn (H.-B.L.); letienthinh@duytan.edu.vn (T.-T.L.); \\ binhpt@utt.edu.vn (B.T.P.)
}

Received: 17 February 2020; Accepted: 23 March 2020; Published: 30 March 2020

\begin{abstract}
Understanding shear behavior is crucial for the design of reinforced concrete beams and sustainability in construction and civil engineering. Although numerous studies have been proposed, predicting such behavior still needs further improvement. This study proposes a soft-computing tool to predict the ultimate shear capacities (USCs) of concrete beams reinforced with steel fiber, one of the most important factors in structural design. Two hybrid machine learning (ML) algorithms were created that combine neural networks (NNs) with two distinct optimization techniques (i.e., the Real-Coded Genetic Algorithm (RCGA) and the Firefly Algorithm (FFA)): the NN-RCGA and the NN-FFA. A database of 463 experimental data was gathered from reliable literature for the development of the models. After the construction, validation, and selection of the best model based on common statistical criteria, a comparison with the empirical equations available in the literature was carried out. Further, a sensitivity analysis was conducted to evaluate the importance of 16 inputs and reveal the dependency of structural parameters on the USC. The results showed that the NN-RCGA $(R=0.9771)$ was better than the NN-FFA and other analytical models $(R=0.5274-0.9075)$. The sensitivity analysis results showed that web width, effective depth, and a clear depth ratio were the most important parameters in modeling the shear capacity of steel fiber-reinforced concrete beams.
\end{abstract}

Keywords: civil engineering; structural engineering; shear capacity; fiber reinforced concrete beams; machine learning; optimization techniques

\section{Introduction}

Concrete is the most popular material in the field of construction [1-3]. However, one of the significant disadvantages of concrete is the weakness of tensile strength and shear resistance. Many studies have been performed to overcome this weakness by focusing on additional components to reinforce concrete [4]. Over the decades, fibers have gained tremendous attention from the research community as a potential improvement to the mechanical properties of concrete [5]. A common type of fiber such as carbon, synthetic, vitreous, or steel is mixed into concrete to enhance the concrete's properties [6]. It is worth mentioning that, since 1972, an important number of studies have been conducted that aimed to replace conventional shear reinforcement with steel fibers (SFs) in reinforced and prestressed concrete [7]. Initially, SFs were used to control plastic and drying shrinkage in concrete. Further studies showed that the addition of SFs in concrete strongly increases 
flexural toughness and tensile strength, the capacity in absorbing energy, ductile behavior, cracking reduction, and improvement of the shear behavior when reinforced [8-10]. For this reason, the use of steel fiber-reinforced concrete (SFRC) has become extensively popular in different civil engineering applications such as tunnel shells, concrete sewer pipes, higher upper layers, and slabs of large industrial buildings [4]. Despite many advantages, designing SFRC structures still faces challenges, as it is difficult to determine critical shear capacity by conventional methods [11-13].

In the literature, various experimental and numerical studies have been performed on SFRC in order to investigate shear strength capacity [10]. Özcan et al. [8] carried out an experimental and finite element modeling using ANSYS software (Version 15, Ansys Inc., Canonsburg, Pennsylvania, United States, 2014) to analyze the ultimate behavior of SFRC beams. Nino Spinella et al. [14] provided a simple physical design model for predicting the shear strength of concrete beams containing fibers, taking into account the width of cracks and shear crack slips. Additionally, an equation based on the basic principle of mechanics has been proposed to estimate the shear strength of SFRC beams using the slenderness ratio [15]. Last but not least, numerous shear tests on prismatic beams have been performed to provide useful information about SFRC [16]. In general, many empirical formulations have been proposed in the literature to estimate SFRC shear strength over the last four decades. However, there is a significant difference between existing experimental results and prediction formulations due to the accuracy and uniformity of the proposed equations [15]. Moreover, mechanical simulations (e.g., the finite element method [17]) or laboratory experiments can only be applied in limited cases. Since laboratory experiments are usually costly and time-consuming, predicting such behaviors remains challenging and requires a robust numerical model for quicker and better results, such as machine learning (ML) approaches [10,18].

In the last two decades, artificial intelligence-based machine learning approaches have been widely used in civil engineering applications [19-31]. As an example of structural engineering, Kiani et al. [32] applied ML techniques, including support vector machines and neural networks, to derive seismic fragility curves. In a series of papers, Mangalathu et al. proposed various machine learning methods such as neural networks and random forest for tracking the damage of bridge portfolios [33], as well as assessing seismic risks of skewed bridges [34]. In terms of structural failure, typical failure modes of reinforced concrete columns such as flexure, flexure-shear, and shear were investigated by Mangalathu et al. [35,36] using decision trees, support vector machines, and neural networks. In terms of structural uncertainty analysis, various published works by E. Zio should be consulted [37-39]. Dao et al. [1] used artificial intelligence approaches (the Adaptive Network-Based Fuzzy Inference System (ANFIS), Artificial Neural Network (ANN), and Support Vector Machine (SVM)) to predict the compressive strength of geopolymer concrete. Ly et al. [40,41] used hybrid artificial intelligence models (Particle Swarm Optimization (PSO) combined with ANFIS - PSOANFIS and Genetic Algorithm (GA) combined with ANFIS - GAANFIS) to predict the critical buckling load of columns or the buckling damage of steel columns under axial compression. Using hybrid artificial intelligence approaches, Dao et al. [42] successfully predicted the compressive strength of geopolymer concrete with steel slag as both coarse and fine aggregates. ML algorithms have also been used to deal with mechanical engineering problems involving the prediction of structural element properties under various solicitations. For instance, Bimal et al. [43] presented the development of neural network (NN) models to predict the shear strength of SFRC beams using various input parameters. However, $\mathrm{NN}$ models usually require many parameters to establish the structure of an NN, such as transfer functions and, in particular, the numbers of neurons and hidden layers. Genetic programming (GP) could be considered as an alternative modeling tool to predict the behavior of structural problems [44]. Additionally, linear genetic programming (LGP), a subset of GP using a linear structure, has been utilized to a derive empirical prediction model that can estimate the shear capacity of SFRC beams without stirrups [10]. Finally, Yaseen et al. [45] developed a support vector regression algorithm optimized with particle swarm optimization to predict the shear strength of SFRC using dimensional and material properties as input parameters. Even though ML approaches have been applied in several 
studies involving SFRC, more effective and accurate approaches should be developed and investigated for different datasets and experimental results. In addition, the importance of input variables used in the ML models should be carried out to select the suitable factors for prediction.

The main objective of this paper is to develop artificial intelligence-based models for the prediction of the ultimate shear capacity (USC) of SFRC and to discuss the influences of input variables. To this aim, two hybrid ML models were constructed that combined NNs with two distinct optimization techniques (i.e., the Real-Coded Genetic Algorithm (RCGA) and the Firefly Algorithm (FFA)): the NN-RCGA and the NN-FFA. A database of 463 samples, including three groups of input variables (geometry of the beam, concrete mixture, and fiber information) and an output variable (USC), was collected and used to generate the training (70\% data) and testing (30\% data) datasets. Statistical measures (e.g., Pearson correlation coefficient (R), root mean squared error (RMSE), and mean absolute error (MAE)) were computed to evaluate the performance of the two proposed ML algorithms. In addition, comparisons between the two models and existing empirical equations were performed. Sensitivity analysis using Individual Conditional Expectation (ICE) and Partial Dependence Plot (PDP) investigations was carried out to reveal the importance of different input variables.

\section{Significance of the Subject}

Many studies have been conducted in the literature regarding the addition of fibers into concrete structures in order to enhance their mechanical properties, especially the ultimate shear capacity. Due to the non-linear behavior between the final response with concrete components, the geometry of concrete beams, and the fiber characteristics, it is difficult to predict the ultimate shear capacity of SFRC beams correctly. Such difficulty might induce costly and time-consuming laboratory or even field experiments. To overcome this problem, ML algorithms such as NNs can contribute as reliable modeling tools to accurately predicting the USCs of SFRC beams. In addition, exploring the importance of input variables using sensitivity analysis can contribute to a better knowledge of the factors affecting the USCs of SFRC beams, which could further recommend promising procedures for experimental researches and facilitate laboratory experiments. Moreover, this numerical prediction model was able to calculate the USC of a single SFRC in less than a second using any personal computer (the function is provided as Supplementary Materials). Therefore, the proposed model could be a potential tool for researchers and structural engineers in estimating the USCs of SFRC accurately (i) within the ranges of values used in this study for the input variables, and (ii) with a reduced time and cost in developing other numerical schemes (e.g., finite element models).

\section{Materials and Methods}

\subsection{Dataset Preparation}

In this study, 463 experimental data on SFRC beams-including input variables (represented by geometry of beams, concrete mixtures, and fiber information) and an output variable (ultimate shear strength of the beams) - were gathered from the available database recently constructed by Lantsoght [46] (the database is available in the public domain in xlsx file format). Table 1 summarizes the database, including the number of data collected in each reference and their percentages of proportion. Table 2 indicates the classification and proportion of each cross-section type, fiber type, and failure mode. 
Table 1. Database collection.

\begin{tabular}{|c|c|c|c|c|c|c|c|}
\hline No & Reference & Number of Data & $\begin{array}{c}\text { Proportion of } \\
\text { Data }(\%)\end{array}$ & No & Reference & Number of Data & $\begin{array}{c}\text { Proportion of } \\
\text { Data (\%) }\end{array}$ \\
\hline 1 & Abdul-Zaher et al. [46] & 3 & 0.65 & 32 & Li and Ward [47] & 22 & 4.75 \\
\hline 2 & Adebar et al. [48] & 6 & 1.30 & 33 & Lim and Oh [49] & 2 & 0.43 \\
\hline 3 & Amin and Foster [50] & 2 & 0.43 & 34 & Lim et al. [51] & 7 & 1.51 \\
\hline 4 & Aoude and Cohen 2014 [52] & 4 & 0.86 & 35 & Lima-Araujo et al. [53] & 2 & 0.43 \\
\hline 5 & Aoude et al. [54] & 4 & 0.86 & 36 & Manju et al. [55] & 6 & 1.30 \\
\hline 6 & Arslan et al. [15] & 9 & 1.94 & 37 & Mansur et al. [56] & 9 & 1.94 \\
\hline 7 & Ashour et al. [57] & 18 & 3.89 & 38 & Minelli and Plizzari [58] & 9 & 1.94 \\
\hline 8 & Bae et al. [12] & 1 & 0.22 & 39 & Narayanan and Darwish [59] & 37 & 7.99 \\
\hline 9 & Batson et al. [60] & 43 & 9.29 & 40 & Noghabai [61] & 15 & 3.24 \\
\hline 10 & Casanova and Rossi [62] & 2 & 0.43 & 41 & Pansuk et al. [11] & 2 & 0.43 \\
\hline 11 & Casanova et al. [63] & 3 & 0.65 & 42 & Parra-Montesinos et al. [64] & 10 & 2.16 \\
\hline 12 & Chalioris and Sfiri 2011 [65] & 1 & 0.22 & 43 & Qissab and Salman [66] & 11 & 2.38 \\
\hline 13 & Cho and Kim [67] & 12 & 2.59 & 44 & Randl et al. [68] & 5 & 1.08 \\
\hline 14 & Cohen and Aoude 2012 [69] & 1 & 0.22 & 45 & Roberts and Ho [70] & 6 & 1.30 \\
\hline 15 & Cucchiara et al. [71] & 4 & 0.86 & 46 & Rosenbusch and Teutsch [72] & 19 & 4.10 \\
\hline 16 & Danygier and Savir [73] & 2 & 0.43 & 47 & Sahoo and Sharma [74] & 7 & 1.51 \\
\hline 17 & Dinh et al. [75] & 19 & 4.10 & 48 & Sahoo et al. [76] & 3 & 0.65 \\
\hline 18 & Dupont and Vandewalle [77] & 20 & 4.32 & 49 & Shoaib [78] (REF prob) & 3 & 0.65 \\
\hline 19 & Furlan and de Hanai [79] & 7 & 1.51 & 50 & Shoaib and Lubell [80] & 2 & 0.43 \\
\hline 20 & Gali and Subramaniam [81] & 2 & 0.43 & 51 & Singh and Jain [82] & 32 & 6.91 \\
\hline 21 & Greenough and Nehdi [83] & 9 & 1.94 & 52 & Spinella et al. [84] & 2 & 0.43 \\
\hline 22 & Huang et al. 2005 [85] & 1 & 0.22 & 53 & Swamy and Bahia [86] & 5 & 1.08 \\
\hline 23 & Hwang et al. [87] & 7 & 1.51 & 54 & Swamy et al. [88] & 7 & 1.51 \\
\hline 24 & Imam et al. [89] & 3 & 0.65 & 55 & Tahenni et al. [90] & 9 & 1.94 \\
\hline 25 & Jindal [91] & 7 & 1.51 & 56 & Tan et al. [92] & 5 & 1.08 \\
\hline 26 & Kang et al. [93] & 5 & 1.08 & 57 & Zamanzadeh et al. [94] & 3 & 0.65 \\
\hline 27 & Kang et al. [95] & 2 & 0.43 & 58 & Zarrinpour and Chao [96] & 5 & 1.08 \\
\hline 28 & Kim et al. [97] & 2 & 0.43 & 59 & Sharma [98] & 1 & 0.22 \\
\hline 29 & Krassowska et al. [99] & 2 & 0.43 & 60 & Shin et al. [100] & 6 & 1.30 \\
\hline 30 & Kwak et al. [101] & 4 & 0.86 & 61 & Zhao et al. [102] & 4 & 0.86 \\
\hline 31 & Kwak and Suh [103] & 4 & 0.86 & & Total & 463 & 100.00 \\
\hline
\end{tabular}


Table 2. Information on the database concerning cross-section type, fiber type, and failure mode.

\begin{tabular}{|c|c|c|c|c|c|c|c|c|}
\hline Cross-Section & $\begin{array}{l}\text { Number } \\
\text { of Data }\end{array}$ & Proportion (\%) & Fiber Type & $\begin{array}{l}\text { Number } \\
\text { of Data }\end{array}$ & Proportion (\%) & Failure Mode & $\begin{array}{l}\text { Number } \\
\text { of Data }\end{array}$ & Proportion (\%) \\
\hline Rectangular & 427 & 92.22 & Hooked & 282 & 60.91 & Diagonal tension & 16 & 4.06 \\
\hline T-type & 18 & 3.89 & Crimped & 109 & 23.54 & $\begin{array}{l}\text { Diagonal tension }+ \\
\text { shear tension }\end{array}$ & 9 & 2.28 \\
\hline I-type & 7 & 1.51 & Straight smooth & 19 & 4.10 & $\begin{array}{l}\text { Diagonal tension }+ \text { shear } \\
\text { tension }+ \\
\text { shear compression }\end{array}$ & 23 & 5.84 \\
\hline \multirow[t]{10}{*}{ Non-prismatic } & 11 & 2.38 & Hooked + straight & 7 & 1.51 & Shear & 258 & 65.48 \\
\hline & & & $\begin{array}{l}\text { Brass-coated high } \\
\text { strength steel }\end{array}$ & 12 & 2.59 & $\begin{array}{l}\text { Shear compression + } \\
\text { shear tension }\end{array}$ & 2 & 0.51 \\
\hline & & & Chopped with butt ends & 1 & 0.22 & $\begin{array}{l}\text { Shear compression }+ \\
\text { shear tension }+ \\
\text { yielding of steel }\end{array}$ & 3 & 0.76 \\
\hline & & & Corrugated & 3 & 0.65 & $\begin{array}{l}\text { Shear tension }+ \\
\text { diagonal tension }\end{array}$ & 4 & 1.02 \\
\hline & & & Flat & 3 & 0.65 & $\begin{array}{l}\text { Shear tension + diagonal } \\
\text { tension }+ \text { bond } \\
\text { degradation near support }\end{array}$ & 3 & 0.76 \\
\hline & & & Flat end & 6 & 1.30 & $\begin{array}{l}\text { Shear tension + diagonal } \\
\text { tension + tension } \\
\text { steel yielding }\end{array}$ & 6 & 1.52 \\
\hline & & & Mill-cut & 4 & 0.86 & Shear, shear-compression & 15 & 3.81 \\
\hline & & & Recycled & 3 & 0.65 & Shear-compression, flexure & 1 & 0.25 \\
\hline & & & Round & 13 & 2.81 & Shear-flexure & 48 & 12.18 \\
\hline & & & Straight mild steel & 1 & 0.22 & Shear-tension & 6 & 1.52 \\
\hline
\end{tabular}


The fiber types in the present dataset contained: hooked (60.9\%), crimped (23.5\%), straight smooth $(4.10 \%)$, hooked + straight $(1.51 \%)$, brass-coated high strength steel $(2.59 \%)$, chopped with butt ends $(0.22 \%)$, flat end $(1.30 \%)$, flat $(0.65 \%)$, corrugated $(0.65 \%)$, mill-cut $(0.86 \%)$, recycled $(0.65 \%)$, round $(2.81 \%)$, and straight mild steel $(0.22 \%)$.

As highlighted in Table 3, the database included four categories of variables: geometry of beams, concrete mixture, fiber information, and ultimate shear capacity. In the geometry of beams category, the considered inputs were web width, height of cross-section, effective depth, span length, shear span, clear shear span, reinforcement ratio, yield strength of reinforcement steel, depth ratio, and clear depth ratio. In the concrete mixture category, the considered inputs were maximum aggregate size and concrete cylinder compressive strength. In the fiber information category, the considered inputs were fiber volume fraction, length/diameter ratio of fibers, tensile strength of fibers, and fiber factor. In the final category, the considered output consisted of the ultimate shear capacity of the beams. These parameters are detailed according to notation, unit, role, and statistical analysis (min, max, average, standard deviation, and coefficient of variation) in Table 3. It can be seen that all the variables exhibited a significant coefficient of variation, ranging from $30 \%$ (yield strength of reinforcement ratio) to $76.43 \%$ (ultimate shear capacity). Such statistical behavior allows, in a positive way, the development of ML algorithms by covering a broad zone of data values. In addition, the data used in this work are randomly divided into two sub-datasets using a uniform distribution, where $70 \%$ of the data is used for training the ML models, and the remaining 30\% data serves as validation. The training dataset is scaled to the range of $[0,1]$ in order to minimize the bias between variables. The scaling parameters of the training dataset are also employed for scaling the corresponding testing dataset so as to prevent pre-correlation. For illustration purposes, Figure 1 displays the correlation graphs and histograms of all input variables versus the ultimate shear strengths of SFRC beams in the present database. However, it should be noticed that this present study did not consider fiber type or failure mode as inputs. Further investigation is needed for evaluating those two parameters.

\subsection{Neural Network (NN)}

In recent decades, the use of NNs has become popular in civil engineering applications [104]. Neural networks belong to a class of machine learning algorithms, and are patterned after the biological process of the human brain [22,105-108]. Input data conditions do not need to be defined while using an NN algorithm. Techniques based on NNs are especially powerful for finding solutions to complex problems that traditional mathematical models have difficulty solving [109]. NNs consist of many node functions that receive, process, and transfer information from one node to another. The processing units in NNs are mainly grouped into input, hidden, and output layers. The main objective of the input layer is to receive, initialize, and transfer input data to the next layer. The hidden layers contain node functions that process and train the model using the given input data. [110].

The NN model exhibits crucial profits not found in traditional computational methods. Hypotheses or constraints are not necessary when optimizing NNs [111-113], and they are also able to analyze and explore complex (even nonlinear) relationships in data [114-116]. From a computational point of view, NNs are powerful at solving high dimensional problems because of their processing capabilities in parallel $[19,117,118]$. Based on the various advantages mentioned previously, the NN model has been employed in the past for predicting the failures of structural elements [32-36,119-122]. 
Table 3. Initial statistical analysis of the database.

\begin{tabular}{|c|c|c|c|c|c|c|c|c|c|c|c|}
\hline Data Type & Variable & Notation & Unit & Role & Min & $\mathrm{Q}_{25}$ & Average & $\mathbf{Q}_{75}$ & Max & StD & CV $(\%)$ \\
\hline \multirow[t]{10}{*}{ Geometry } & Web width & $b_{\mathrm{W}}$ & $\mathrm{mm}$ & Input & 50.00 & 100.00 & 140.58 & 152.40 & 310.00 & 50.75 & 36.10 \\
\hline & Height of cross-section & $\mathrm{H}$ & $\mathrm{mm}$ & Input & 100.00 & 180.00 & 284.75 & 303.60 & 1000.00 & 140.19 & 49.23 \\
\hline & Effective depth & $\mathrm{d}$ & $\mathrm{mm}$ & Input & 85.25 & 140.00 & 245.37 & 266.00 & 910.00 & 126.79 & 51.67 \\
\hline & Span length & $1_{\text {span }}$ & $\mathrm{mm}$ & Input & 204.00 & 1160.00 & 1816.70 & 2220.00 & 5600.00 & 888.97 & 48.93 \\
\hline & Shear span & $\mathrm{a}$ & $\mathrm{mm}$ & Input & 102.00 & 392.50 & 713.64 & 875.00 & 2800.00 & 438.39 & 61.43 \\
\hline & Clear shear span & $a_{v}$ & $\mathrm{~mm}$ & Input & 52.40 & 337.50 & 639.20 & 775.00 & 2700.00 & 418.44 & 65.46 \\
\hline & Reinforcement ratio & $\varrho$ & $\%$ & Input & 0.37 & 1.72 & 2.43 & 3.09 & 5.72 & 0.01 & 41.39 \\
\hline & Yield strength of reinforcement steel & $\mathrm{f}_{\mathrm{y}}$ & $\mathrm{MPa}$ & Input & 275.86 & 420.00 & 469.96 & 530.00 & 900.00 & 98.59 & 20.98 \\
\hline & Depth ratio & $\mathrm{a} / \mathrm{d}$ & - & Input & 0.70 & 2.31 & 2.93 & 3.50 & 6.00 & 0.98 & 33.66 \\
\hline & Clear depth ratio & $a_{v} / d$ & - & Input & 0.41 & 2.00 & 2.60 & 3.17 & 5.95 & 0.95 & 36.56 \\
\hline \multirow[t]{2}{*}{ Concrete mix } & Maximum aggregate size & $\mathrm{d}_{\text {aggmax }}$ & $\mathrm{mm}$ & Input & 0.40 & 9.55 & 10.66 & 13.00 & 22.00 & 5.11 & 47.93 \\
\hline & $\begin{array}{l}\text { Average measured concrete cylinder } \\
\text { compressive strength }\end{array}$ & $\mathrm{f}_{\mathrm{c}}{ }^{\prime}$ & $\mathrm{MPa}$ & Input & 9.77 & 33.22 & 47.98 & 54.10 & 215.00 & 24.17 & 50.37 \\
\hline \multirow[t]{4}{*}{ Fiber } & Fiber volume fraction & $\mathrm{V}_{\mathrm{f}}$ & $\%$ & Input & 0.20 & 0.50 & 0.88 & 1.00 & 4.50 & 0.56 & 63.30 \\
\hline & Length/diameter ratio of fibers & $\mathrm{l}_{\mathrm{f}} / \mathrm{d}_{\mathrm{f}}$ & - & Input & 25.00 & 60.00 & 71.87 & 80.00 & 190.50 & 24.72 & 34.40 \\
\hline & Tensile strength of fibers & $f_{\text {tenfiber }}$ & $\mathrm{MPa}$ & Input & 260.00 & 1100.00 & 1241.73 & 1200.00 & 4913.00 & 457.82 & 36.87 \\
\hline & Fiber factor & $\mathrm{F}$ & - & Input & 0.075 & 0.300 & 0.536 & 0.698 & 2.858 & 0.365 & 68.10 \\
\hline Capacity & Ultimate shear capacity & $\mathrm{V}_{\mathrm{u}}$ & $\mathrm{N}$ & Output & $12,824.46$ & $45,000.00$ & $124,010.51$ & $170,277.39$ & $396,000.00$ & $94,784.90$ & 76.43 \\
\hline
\end{tabular}




\subsection{Selection of Global Optimization Techniques}

Aside from traditional gradient-based optimization techniques [123], various metaheuristic methods have been proposed in the literature in order to optimize the weight parameters of the NN model, for instance: Artificial Bee Colony [124], Genetic Algorithm [125], Simulated Annealing [126], Hierarchical k-Means Clustering [127], and Particle Swarm Optimization [5]. Training of a NN model based on gradient of error can be very unstable when searching for a global minimum [128]. Indeed, gradient-based techniques might not escape a local minimum to find a global one [129]. The performance is also dependent on the values of an initial guess, which is generally difficult to choose $[128,130]$. Moreover, in most structural experiments, the variables are generally obtained as discrete. Consequently, constraints (e.g., stress, displacement) are not explicit (the implicit form of constraints can be achieved only from analytical or finite element models) [131-134]. Therefore, for structural optimization problems, various nature-inspired global optimization techniques have been introduced to overcome these inconveniences, as demonstrated in the literature $[5,124,126,135,136]$. In this paper, two global optimization techniques were employed, the Real-Coded Genetic Algorithm and the Firefly Algorithm, for calibrating the weight parameters of the NN model.
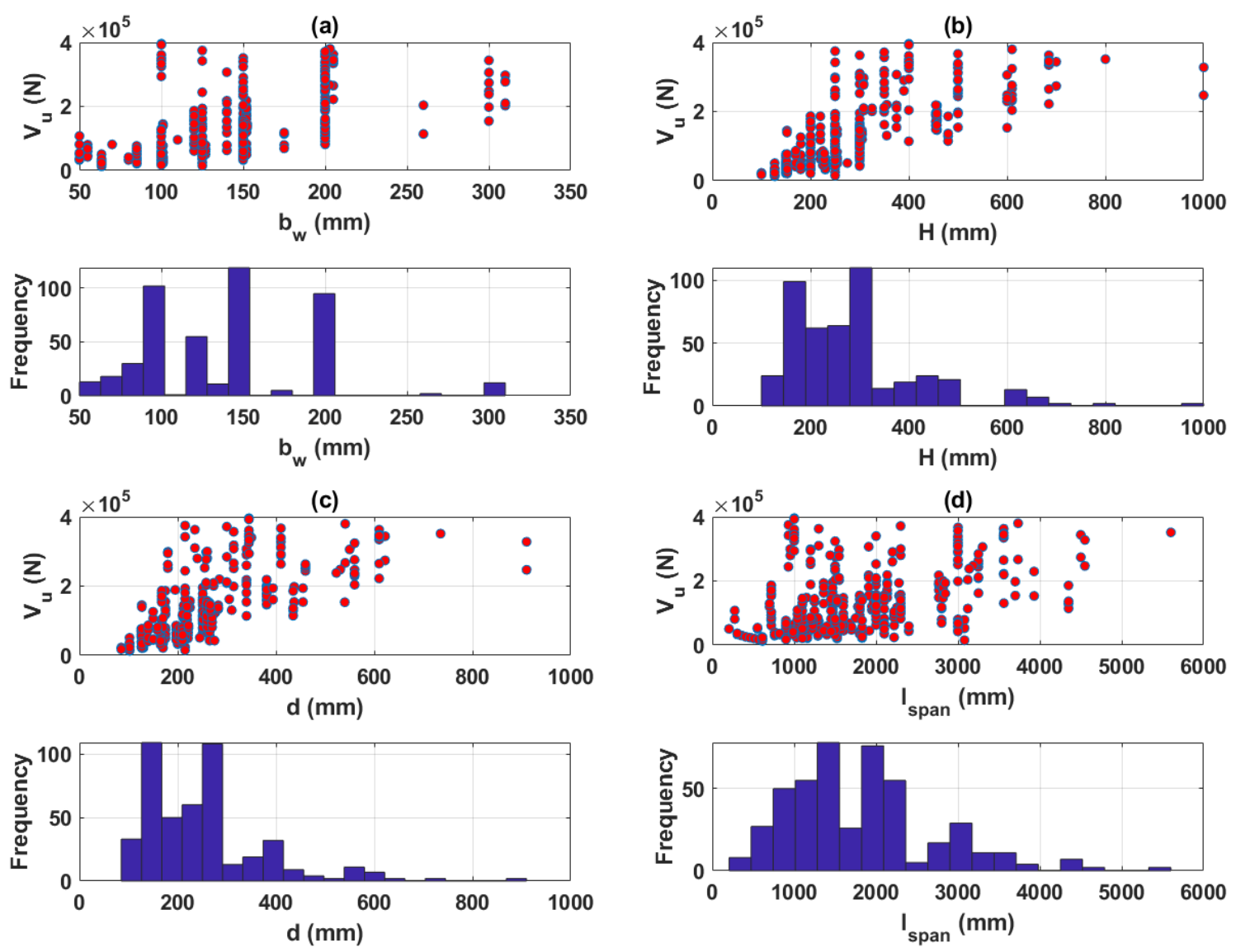

Figure 1. Cont. 

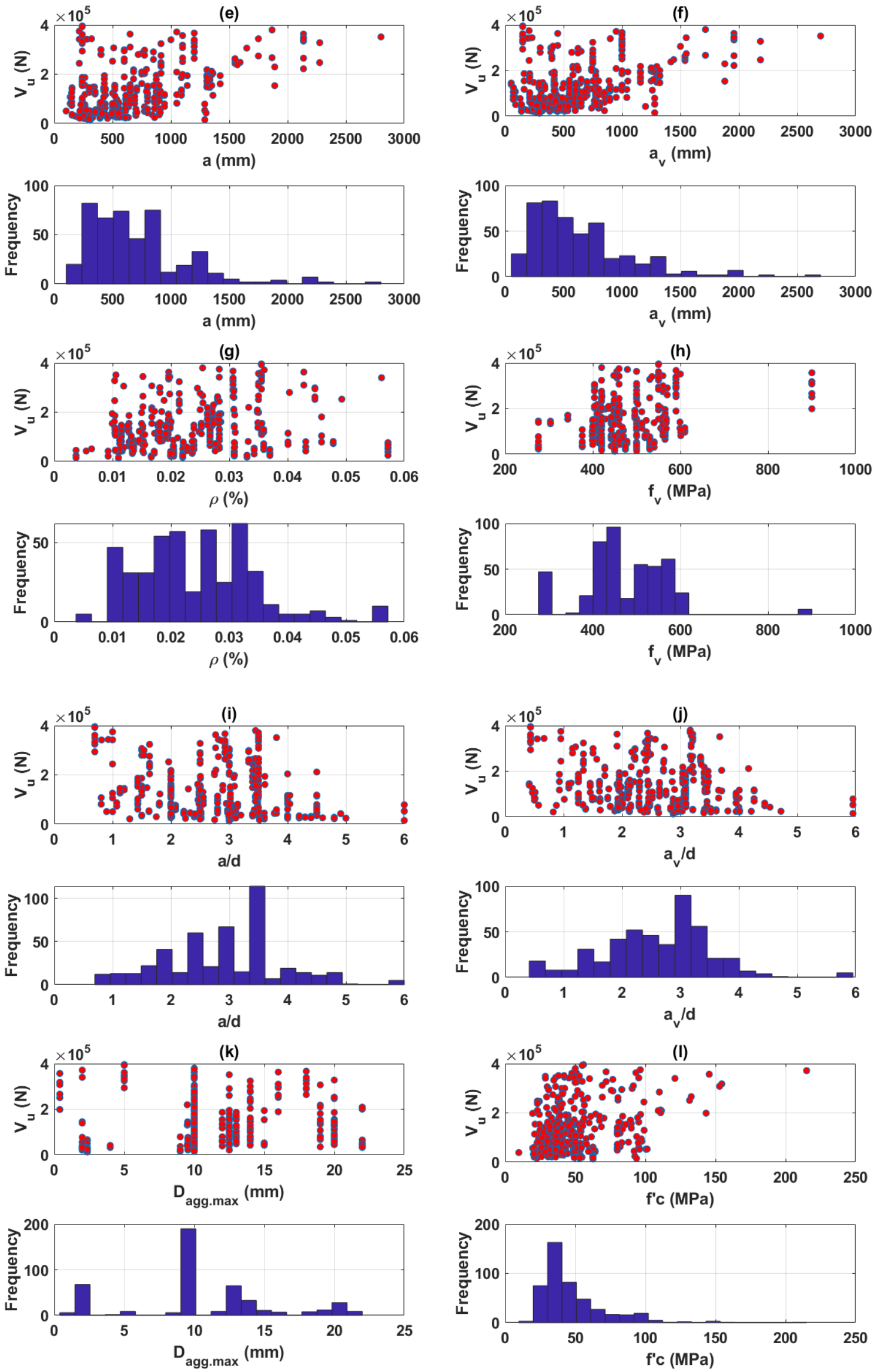

Figure 1. Cont. 

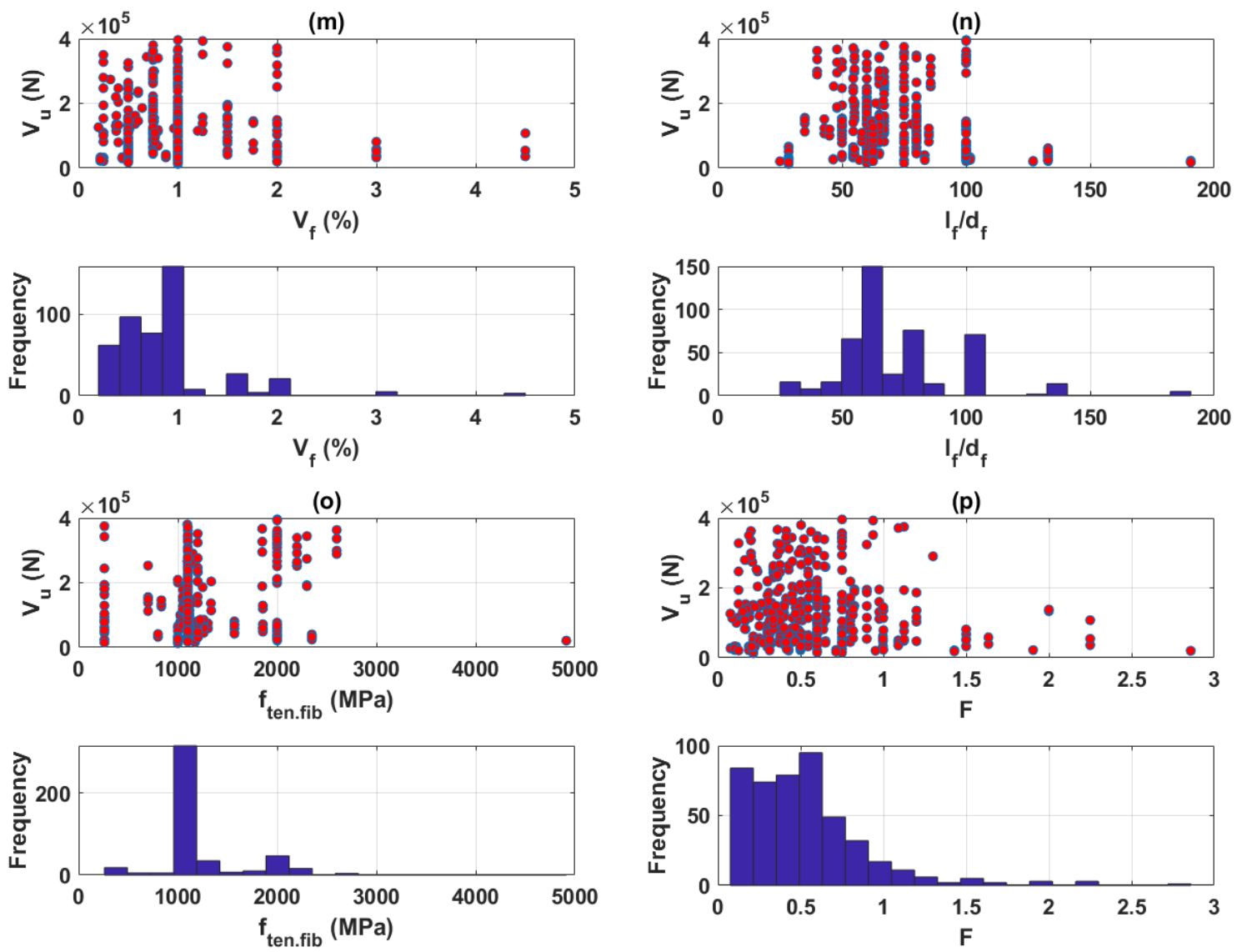

Figure 1. Histograms of the parameters: (a) web width; (b) height of cross-section; (c) effective depth; (d) span length; (e) shear span; (f) clear shear span; (g) reinforcement ratio; (h) yield strength of reinforcement steel; (i) depth ratio; (j) clear depth ratio; (k) maximum aggregate size; (1) concrete compressive strength; (m) fiber volume fraction; (n) length/diameter ratio of fibers; (o) tensile strength of fibers; and (p) fiber factor.

\subsection{Real-Coded Genetic Algorithm (RCGA)}

Derived from the principles of biological evolution, the RCGA is an optimization technique that has been used immensely since its first introduction and investigation by John Holland [137]. It is known as a searching method containing three evolutionary operations-reproduction, crossover, and mutation - by which to solve complex problem [138]. In the RCGA, the search space parameters are represented as strings, called "chromosomes", and a population is defined as a collection of such strings. A random population, which represents various points in the search space, is initially created. Each string is then correlated with an objective and fitness function that defines the degree of goodness of the string. Based on the survival of the fittest principle, a few strings are selected, and several copies are assigned to each one going into the mating pool. Such strings are used by biologically motivated operators (e.g., cross-over and mutation) to produce a new set of strings. The selection, crossover, and mutation process will continue for a fixed number of generations until certain conditions are matched $[139,140]$. The process of the RCGA experimental search diagram is presented in Figure 2. 


\begin{tabular}{|c|c|c|c|c|c|c|c|c|c|}
\hline \multirow{2}{*}{ (a) } & \multirow[b]{2}{*}{ N1 } & \multirow{2}{*}{\multicolumn{2}{|c|}{\begin{tabular}{l|l}
0 & 0 \\
\end{tabular}}} & \multirow{2}{*}{\multicolumn{2}{|c|}{\begin{tabular}{l|l}
0 & 0 \\
\end{tabular}}} & \multirow{2}{*}{\begin{tabular}{|l|l|}
0 \\
\end{tabular}} & \multirow{2}{*}{\multicolumn{2}{|c|}{\begin{tabular}{|l|l|}
0 & 0 \\
\end{tabular}}} & \multirow{2}{*}{0} \\
\hline & & & & & & & & & \\
\hline & $\mathrm{N} 2$ & 1 & 1 & 1 & 1 & 1 & $1 \mid 1$ & \begin{tabular}{l|l}
1 & 1 \\
\end{tabular} & \\
\hline \multirow{3}{*}{ Chromosome } & N3 & 1 & 0 & 1 & 0 & 1 & 0 & 10 & \\
\hline & N4 & 1 & 1 & 0 & 1 & 1 & \begin{tabular}{l|l}
0 & 1 \\
0
\end{tabular} & \begin{tabular}{l|l}
1 & 1 \\
1
\end{tabular} & \\
\hline & N5 & 1 & 1 & 1 & 0 & 1 & 11 & 10 & \\
\hline Population & N6 & 1 & 1 & 1 & 1 & 0 & 111 & 1 & 1 \\
\hline
\end{tabular}

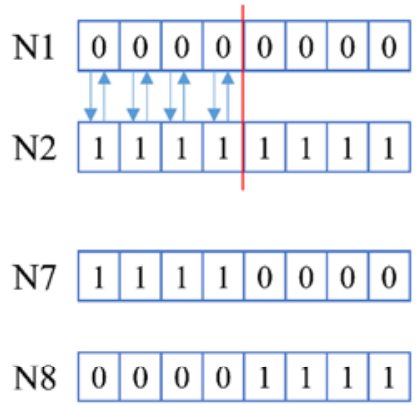

(b)

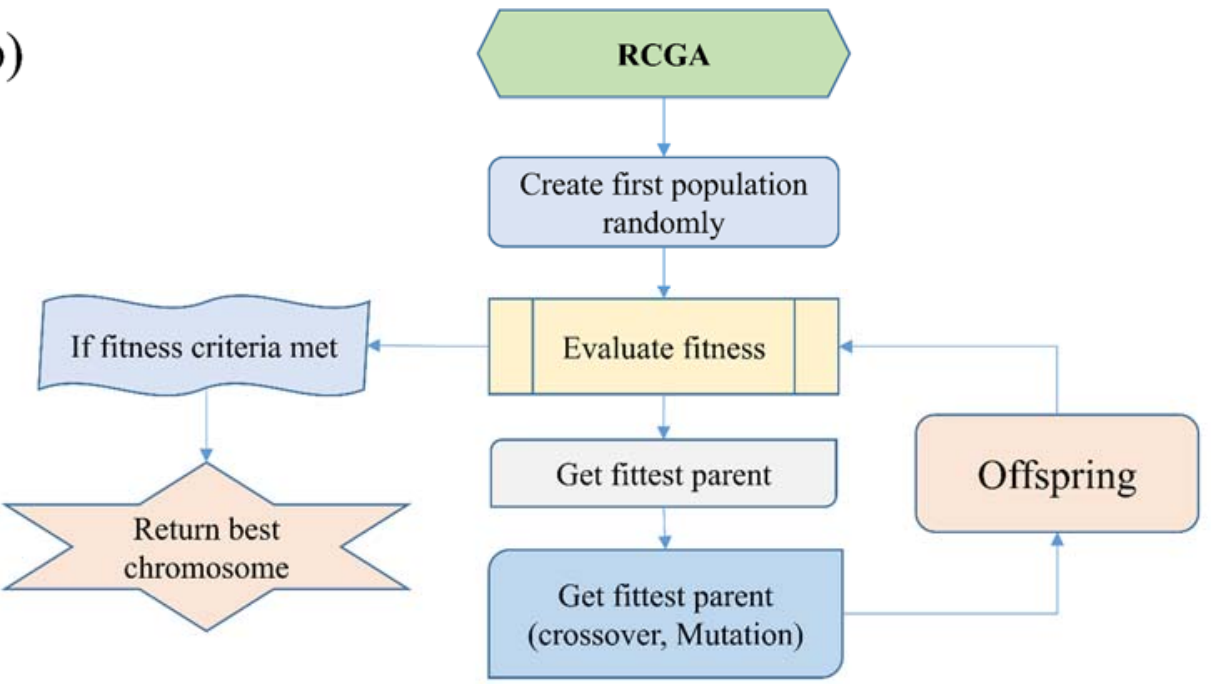

Figure 2. (a) The Real-Coded Genetic Algorithm (RCGA) crossover operator and mutation operator for offspring chromosomes; (b) the structure of the RCGA.

The RCGA technique has been successfully applied in various optimization problems of different scientific fields. Blanco et al. [128] combined the RCGA and recurrent neural networks to perform fuzzy grammatical inference. In another study, Sedki et al. [141] forecast daily rainfall runoff when calibrating the weight parameters of an NN according to the RCGA technique. The main advantages of using the RCGA for training artificial intelligence-based models have been reported in various works, showing that the RGCA is robust in finding the global minimum, including cases of noisy or stochastic objective functions $[129,141,142]$.

\subsection{Firefly Algorithm (FFA)}

The FFA, which is based on the flashing behavior of fireflies, is a metaheuristic algorithm. Fireflies use bioluminescence and varied flashing patterns (referred to as "bioluminescent communication") to communicate, search for prey, and find mates. This phenomenon is often used to optimize parameters of machine learning algorithms, such as NNs or the Adaptive Network-based Fuzzy Inference System (ANFIS) [143]. The basic principles of FFA can be summarized as: (i) the fireflies are unisexual and any firefly can be attracted to any other firefly; (ii) a firefly's attractiveness is directly proportional to the firefly's brightness, and the brightness reduces when the distance traveled rises; (iii) fireflies shift randomly if they cannot find an attractive firefly in neighboring regions [144]. The FFA measures each firefly's brightness and relative attractiveness, as a firefly's' location changes based on these two values. All fireflies converge at the best possible position in a search space after a sufficient number of iterations [144]. The FFA could be considered a swarm intelligence based-algorithm like Particle Swarm Optimization (PSO) or Artificial Bee Colony (ABC), which are based on a population finding 
the global optima of an objective function [145]. However, FFA is observed to be superior in many scenarios [146]. A diagram of the FFA's experimental search process is depicted in Figure 3.

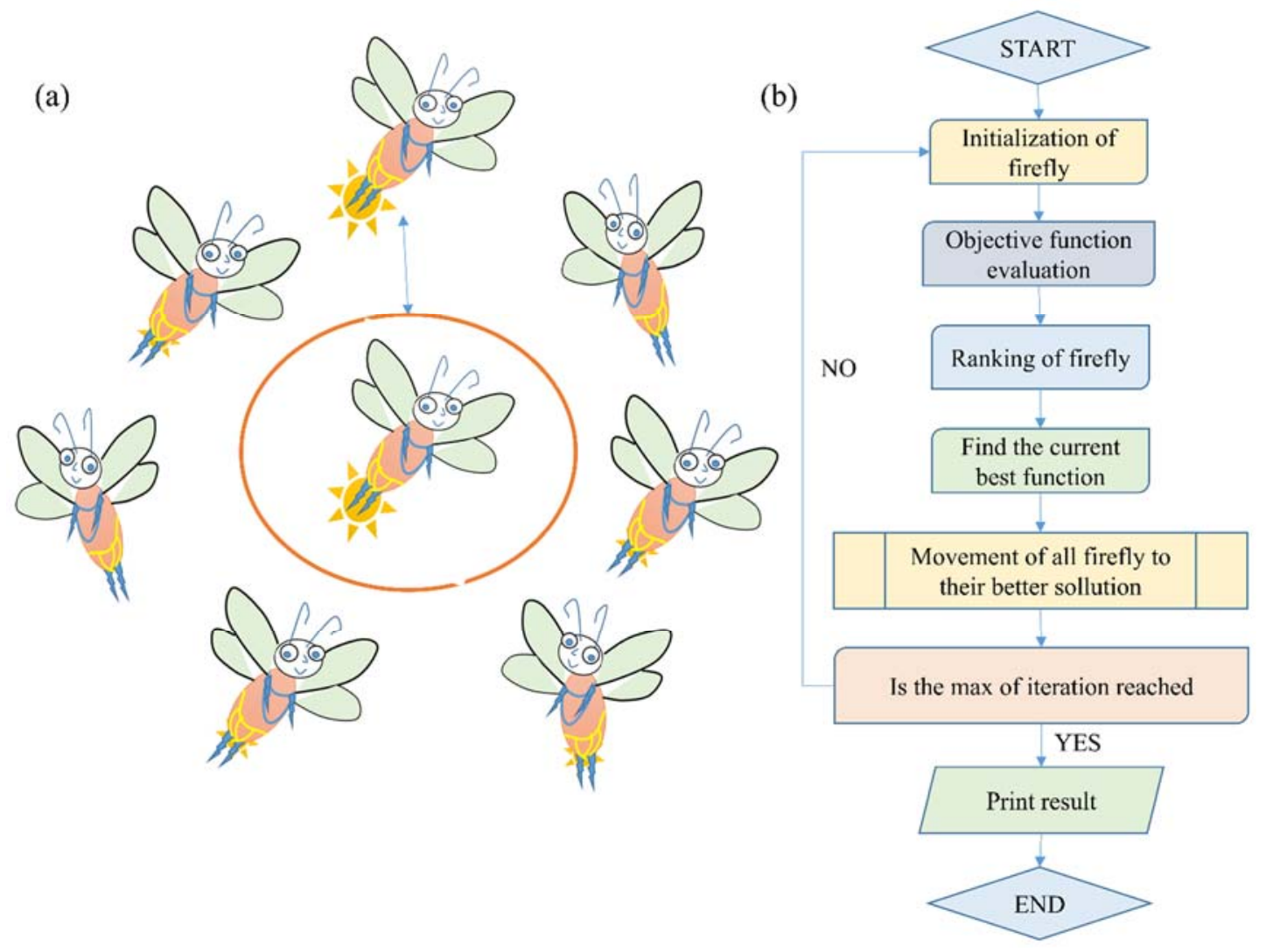

Figure 3. (a) Fireflies with updated position; (b) the structure of the Firefly Algorithm (FFA).

\subsection{Machine Learning Evaluation Criteria}

In the present study, Pearson correlation coefficient (R), mean absolute error (MAE), and root mean squared error (RMSE) were used as evaluation criteria to validate the developed ML algorithms. Precisely, the $\mathrm{R}$ values allow the statistical relationship between experimental results to be identified, and ML to predict the USC $[147,148]$ by yielding a value between 0 and 1 , where 0 is no correlation and 1 is a total correlation. In the cases of RMSE and MAE, which have the same units as the quantity being estimated [24,42], lower values of RMSE and MAE indicate a basically good accuracy of the prediction output using the ML models [149-154]. The values of R, RMSE, and MAE are estimated using the following equations $[107,108,115,147]$ :

$$
\begin{gathered}
\text { MAE }=\frac{\sum_{i=1}^{n}\left|p_{i}-v_{i}\right|}{n} \\
\mathrm{RMSE}=\sqrt{\sum_{i=1}^{n} \frac{\left(p_{i}-v_{i}\right)^{2}}{n}} \\
\mathrm{R}=\sqrt{\frac{\sum_{i=1}^{n}\left(p_{i}-\bar{p}\right)\left(v_{i}-\bar{v}\right)}{\sqrt{\sum_{i=1}^{n}\left(p_{i}-\bar{p}\right)^{2}} \sum_{i=1}^{n}\left(v_{i}-\bar{v}\right)^{2}}}
\end{gathered}
$$

where $n$ is the number of samples; $p_{i}$ and $v_{i}$ are the actual and predicted outputs, respectively; and $\bar{p}$ and $\bar{v}$ are the mean of the actual and predicted outputs, respectively. 


\section{Results and Analysis}

\subsection{Construction of the Hybrid Models (NN-RCGA and NN-FFA)}

As demonstrated in the literature, the capability of an NN model depends highly on the selected architecture [124,155-158]. Therefore, the determination of an appropriate architecture is required to study an NN model. More precisely, such architecture is determined through the number of hidden layer(s) and the number of neuron(s) in each hidden layer. As revealed by various works in the literature, NN's architecture using one hidden layer can handle complex problems while also saving computation time and cost [142,153,159]. In this study, NN's architecture using one hidden layer was finally chosen, and there were ten neurons in that hidden layer, exhibiting a total number of weight parameters of 181 .

Table 4 shows the characteristics of the NN, while Tables 5 and 6 show the final parameters selected for the RCGA and FFA optimization techniques, respectively, obtained after parametric studies [160]. It is worth noticing that certain ranges of values of parameters are commonly employed for training NN models; for instance, Blanco et al. [128], Irani et al. [129], and Sedki et al. [141] for the RCGA algorithm, while Bui et al. [161] and Sulaiman et al. [162] for the FFA algorithm. Optimization costs of the two hybrid models developed are plotted in Figure 4 involving RMSE, MAE, and R. The RMSE, MAE, and $R$ values are used to assess the prediction performance regarding number of iterations. It was observed that the number of iteration increases could decrease the RMSE and MAE values, whereas the $R$ values tended to increase. As a result, the maximum number of iterations for the NN-FFA was 200, while for the NN-RCGA it was 500. These values were selected when the relative error between two iterations was inferior to $1 \%$. It can be seen that the cost function of testing was highly correlated with training, exhibiting that a no-overfitting zone was established. As such it can be reported that both the FFA and RCGA optimization techniques were efficient in finding the global optimum for the problem.

Table 4. NN characteristics.

\begin{tabular}{cc}
\hline Parameter & Value and Description \\
\hline Neurons in the input layer & 16 \\
Hidden layers & 1 \\
Neurons in hidden layer & 10 \\
Neurons in the output layer & 1 \\
Hidden layer activation function & Sigmoid \\
Output layer activation function & Linear \\
Cost function & Mean square error \\
Size of weight of matrix of hidden layer & $10 \times 16$ \\
Size of bias vector of hidden layer & $1 \times 10$ \\
Size of weight of matrix of the output layer & $1 \times 10$ \\
Size of bias vector of output layer & $1 \times 1$ \\
Total number of parameters & 181 \\
\hline
\end{tabular}

Table 5. Parameters of the FFA used in this study.

\begin{tabular}{cc}
\hline Parameter & Value and Description \\
\hline Number of fireflies & 30 \\
Maximum iteration number & 200 \\
Coefficient of light absorption & 1 \\
Coefficient of attraction & 2 \\
Mutation coefficient & 0.2 \\
Mutation coefficient damping ratio & 0.98 \\
Range of uniform mutation & $5 \%$ \\
Initial damp mutation coefficient & 0.196 \\
\hline
\end{tabular}


Table 6. Parameters of the RCGA used in this study.

\begin{tabular}{cc}
\hline Parameter & Value and Description \\
\hline Population size & 70 \\
Maximum number of iterations & 500 \\
Length of chromosome & 220 \\
Fitness function & linear ranking \\
Cross-over type & random pair \\
Cross-over probability & 0.4 \\
Number of off-springs & 10 \\
Mutation type & random \\
Mutation probability & 0.7 \\
Number of mutants & 18 \\
Selection function & roulette wheel selection \\
\hline
\end{tabular}

\subsection{Validation and Comparison of the Hybrid Models}

Figure $5 \mathrm{a}, \mathrm{c}$ shows the prediction performance between the scaled predicted and actual values of the USCs of concrete beams on the training dataset for the NN-FFA and NN-RCGA. Figure $5 b, d$ shows the same information corresponding to the testing dataset. These results suggest that the performances of the two developed hybrid models were similar. However, the NN-RCGA was slightly superior to the NN-FFA when comparing results obtained from the testing datasets (i.e., $R=0.965$ for NN-FFA and R $=0.979$ for NN-RCGA). In addition to MAE, RMSE, and R (Table 7), a straight line was fit to the predicted versus actual plots. The slope of the linear fit was used to measure the angle between the $\mathrm{x}$-axis and the linear fit, with angles closer to $45^{\circ}$ indicating better performance. As observed, for the training part, the NN-FFA and NN-RCGA yielded slope angles of $42.65^{\circ}$ and $43.53^{\circ}$, respectively. For the testing dataset, the NN-FFA and NN-RCGA produced slope angles of $42.52^{\circ}$ and $43.86^{\circ}$, respectively. Figure 6 shows a histogram of the distribution of errors of the NN-FFA and NN-RCGA in predicting the USCs of concrete beams using the training and testing datasets. It is observed that the NN-RCGA had a higher peak of error concentration around 0 than the NN-FFA in both cases. In general, although both models performed well and were statistically significant, the NN-RCGA proved slightly superior to the NN-FFA in modeling the ultimate shear capacity of concrete beams.

\subsection{Sensitivity Analysis Using ICE and PDP Concepts}

The ICE plots of each simulation show how the output response changed according to the change of the selected input variable. The values of each line were obtained by computing by varying the selected feature using values from a grid while keeping all other features unchanged. The next step consisted of applying the ML model for the recently created values. The obtained results appeared in point form for each instance, with analyses of values of each feature from the grid and corresponding predictions. On the other hand, a PDP is an alternative approach to analyzing the dependence of the predicted output versus input variables [163]. The average of all ICE plots gives the PDP, which represents the influence of the corresponding input to the output for the whole dataset. Table 8 summarizes the obtained results of the PDPs for 16 input variables considered in this work. The importance of the inputs can be grouped into several classes, such as very important factors, important factors, slightly important factors, and not important factors. Results of these classes are given in the following sections. 

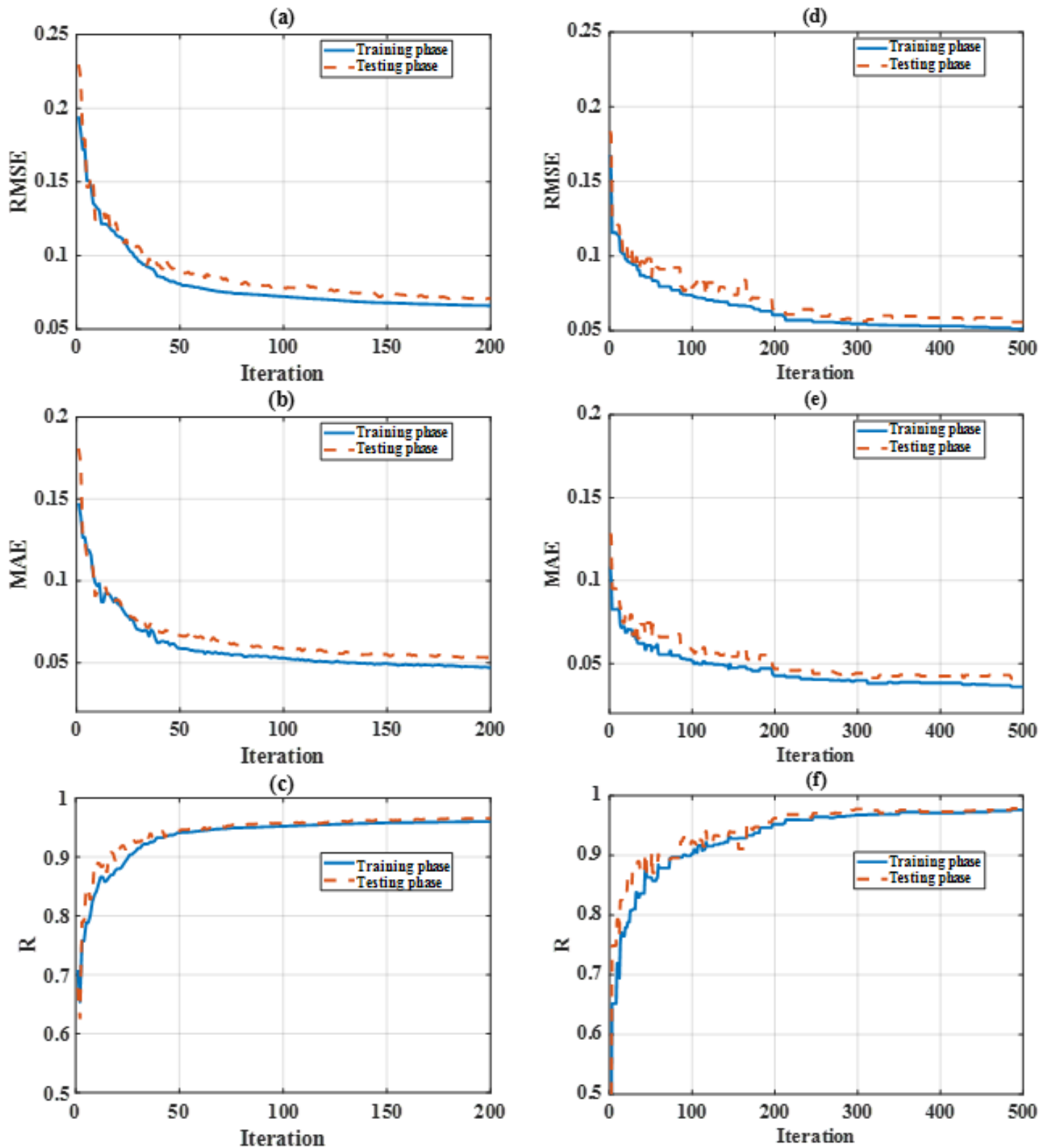

Figure 4. Optimization of the NN using the FFA: (a) RMSE, (b) MAE, (c) R; using RCGA: (d) RMSE, (e) MAE, (f) R. 
(a)

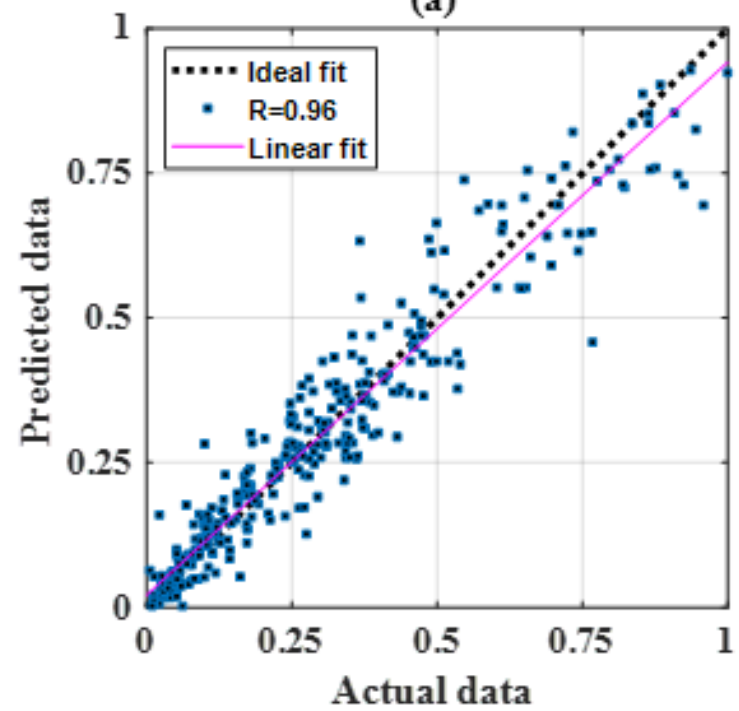

(c)

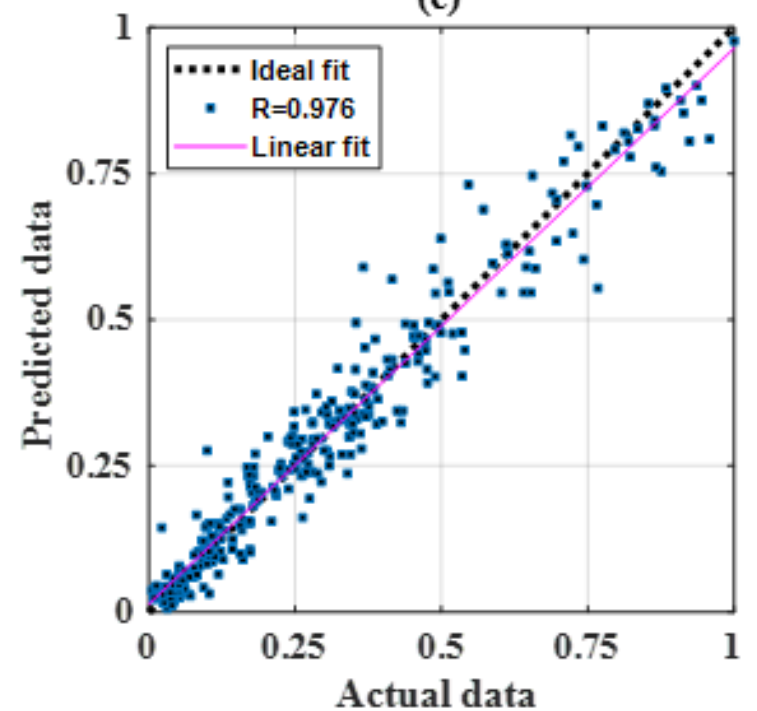

(b)

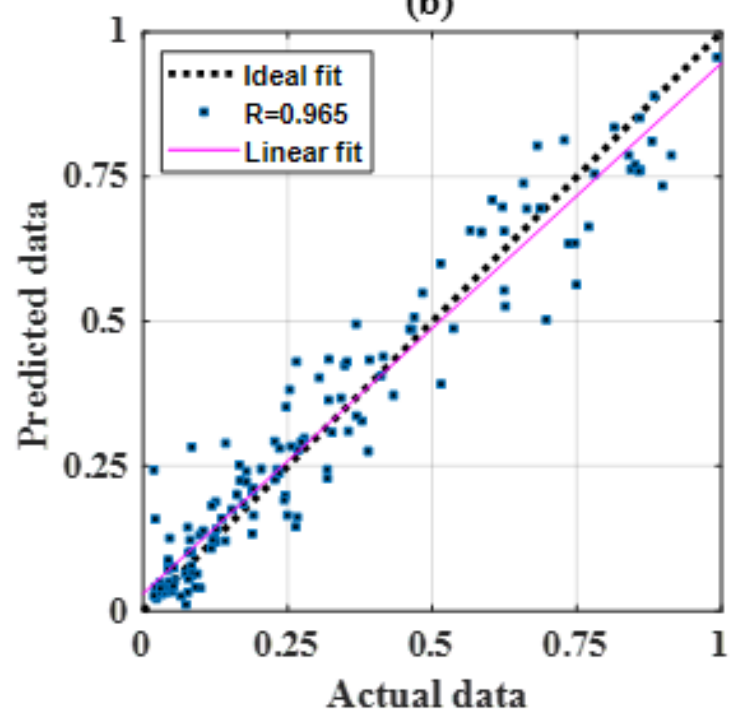

(d)

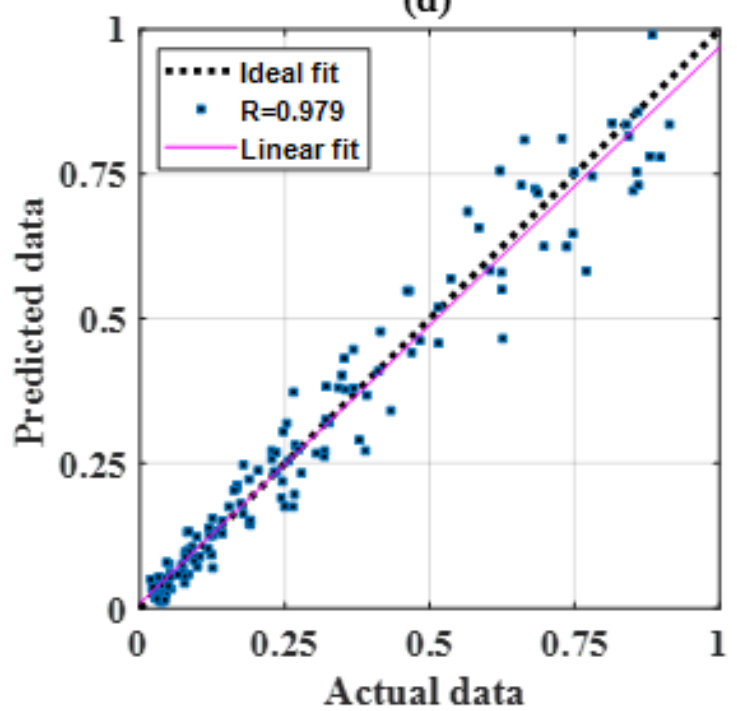

Figure 5. Prediction regression graphs for the training data using (a) the NN-FFA and (c) the NN-RCGA; and for testing data using (b) the NN-FFA and (d) the NN-RCGA.

Table 7. Prediction capability of the hybrid models.

\begin{tabular}{cccccccc}
\hline Method & Dataset & R & RMSE & MAE & Slope & Err.Mean & Err.Std \\
\hline \multirow{2}{*}{ NN-FFA } & Training & 0.960 & 0.066 & 0.047 & 0.921 & 0.001 & 0.066 \\
& Testing & 0.965 & 0.071 & 0.053 & 0.917 & -0.004 & 0.071 \\
\hline \multirow{2}{*}{ NN-RCGA } & Training & 0.976 & 0.051 & 0.036 & 0.950 & 0.000 & 0.051 \\
& Testing & 0.979 & 0.056 & 0.041 & 0.961 & 0.003 & 0.056 \\
\hline
\end{tabular}




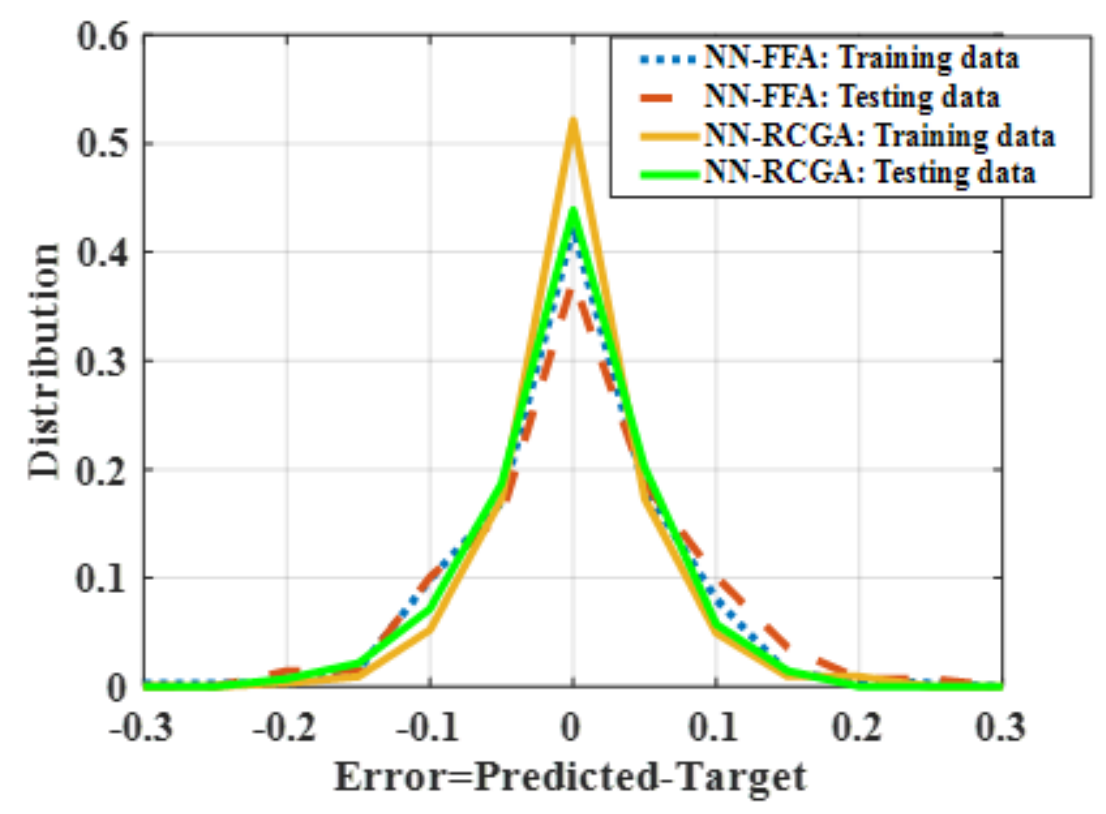

Figure 6. Distribution of error between predicted and actual data.

\subsubsection{Not Important Factors}

As indicated in Table 8 and Figure 7, clear shear span, maximum aggregate size, fiber volume fraction, and tensile strength of fibers are variables that can be considered not important in the prediction of the USCs of SFRC beams. The maximum variation values of the ultimate shear capacity while varying these factors were $0.0551,0.0678,0.0611$, and 0.0118 , respectively. A perfect linear relationship was observed between maximum aggregate size and the ultimate shear capacity. With respect to clear shear span, fiber volume fraction, and tensile strength of fibers, nonlinear relationships were found in which maximum values were obtained in the 0.4-0.6 ranges of the corresponding variables. This means that in order to obtain higher values of ultimate shear capacity, the variables should be selected around their average values. Furthermore, increasing the maximum aggregate size could slightly increase the ultimate shear capacity. Overall, the influences of varying these factors on the ultimate shear capacity were rather small (Table 8). As a result, with the presence of the clear shear span, maximum aggregate size, fiber volume fraction, and tensile strength of fibers, the predicted target was reasonably unchanged.

\subsubsection{Slightly Important Factors}

As shown in Table 8 and Figure 8, the length/diameter ratios of fibers, yield strengths of reinforcement steel, and depth ratios could be considered slightly important variables in predicting the USCs of SFRC beams. The maximum variation values of the ultimate shear capacity while varying these factors were $0.1013,0.1175$, and 0.1225 , respectively. Perfect linear relationships between the yield strength of reinforcement steel, length to diameter ratio of fibers, and ultimate shear capacity were found. The depth ratio seemed to have an exponential relationship with the ultimate shear capacity. However, the latter remained at a constant value when the depth ratio was higher than 0.6. These results could indicate that in order to obtain higher values of ultimate shear capacity, the yield strength of steel should be maximized, whereas a depth ratio larger than 0.6 cannot further enhance the mechanical behavior of SFRC beams. Furthermore, the fiber aspect ratio, or length to diameter ratio of fiber, is not an important influencing factor, as confirmed in a previous work [164]. Overall, the influences of varying these factors on the ultimate shear capacity were rather small (Table 8). As a result, with the presence of the length/diameter ratio of fibers, yield strength of reinforcement steel, and depth ratio, the predicted ultimate shear capacity was slightly changed. 
Table 8. Summary of the Individual Conditional Expectation (ICE) variation and classification of the importance of variables.

\begin{tabular}{clcccc}
\hline Group & \multicolumn{1}{c}{ Variable } & Min & Max & End & Class \\
\hline \multirow{5}{*}{ Geometry } & Web width & 0 & 0.5243 & 0.5243 & 2 \\
& Height of cross-section & 0 & 0.2911 & 0.2285 & 5 \\
& Effective depth & 0 & 0.4238 & 0.4238 & 3 \\
& Span length & -0.2028 & 0 & -0.2028 & 8 \\
& Clear span & 0 & 0.2520 & 0.2520 & 4 \\
& Reinforcement ratio & -0.0551 & 0 & -0.0022 & 16 \\
& Yield strength of reinforcement steel & 0 & 0.1906 & 0.1906 & 9 \\
& Depth ratio & 0 & 0.1175 & 0.1175 & 11 \\
& Clear depth ratio & 0 & 0.1225 & 0.1093 & 10 \\
Concrete & Maximum aggregate size & -0.7246 & 0 & -0.7246 & 1 \\
\hline mix & Average measured concrete cylinder & -0.0678 & 0 & -0.0678 & 15 \\
& compressive strength & 0 & 0.2217 & 0.1523 & 7 \\
\hline \multirow{2}{*}{ Fiber } & Fiber volume fraction & 0 & 0.0611 & 0.0303 & 14 \\
& Length/diameter ratio of fibers & -0.1013 & 0 & -0.1013 & 12 \\
& Tensile strength of fibers & -0.0061 & 0.0118 & -0.0061 & 13 \\
& Fiber factor & 0 & 0.2342 & 0.2342 & 6 \\
\hline
\end{tabular}
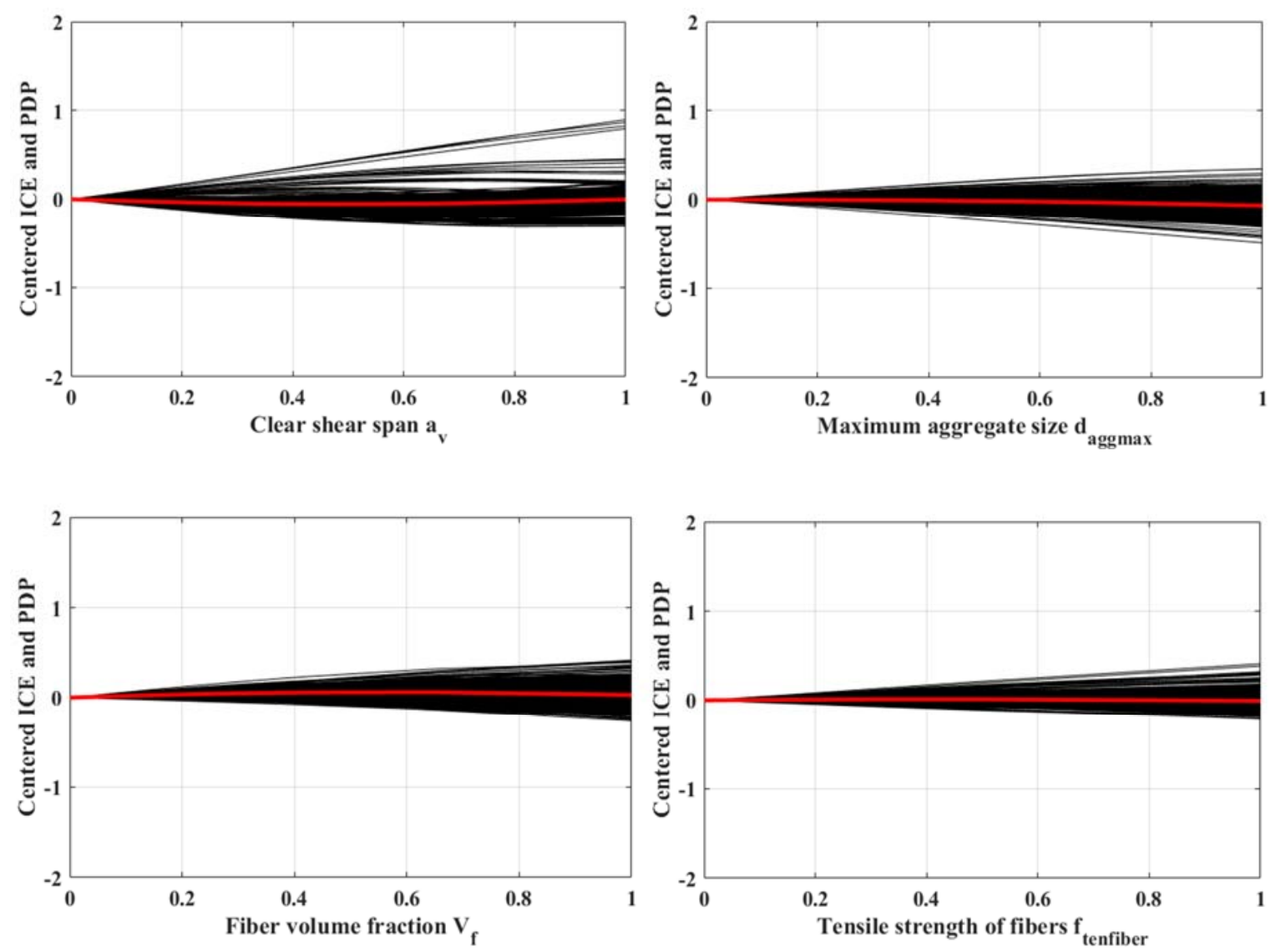

Figure 7. ICE (black lines) and Partial Dependence Plot (PDP) (red lines) of clear shear span, maximum aggregate size, fiber volume fraction, and tensile strength of fibers obtained from the NN-RCGA model. 

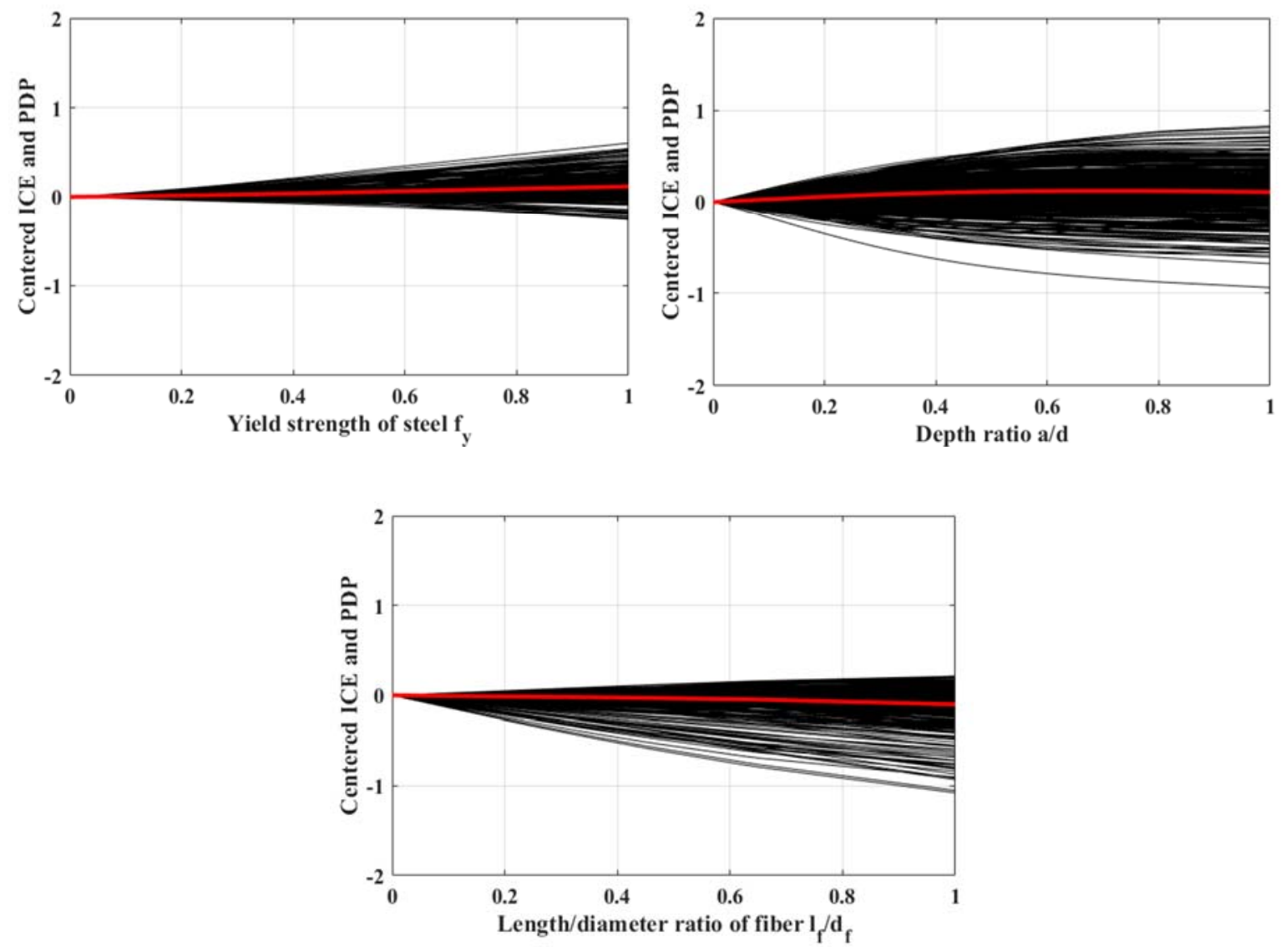

Figure 8. ICE (black lines) and PDPs (red lines) of yield strength, depth ratio, and length-diameter ratio of fiber obtained from the NN-RCGA model.

\subsubsection{Important Factors}

As shown in Table 8 and Figure 9, shear span, height of cross-section, fiber factor, average measured concrete cylinder compressive strength, span length, and reinforcement ratio are important variables in predicting the USCs of SFRC beams. The maximum variation values of the ultimate shear capacity while varying these factors were $0.2520,0.2911,0.2342,0.2217,0.2028$, and 0.1906 , respectively. The span length and fiber factor correlated with the ultimate shear capacity in a perfectly linear manner, whereas nonlinear relationships were found between height of cross-section, shear span, concrete compressive strength, and reinforcement ratio with the ultimate shear capacity. The latter reached its maximum value when the height of the cross-section was about 0.8 and the shear span about 0.9 . A reinforcement ratio ranging from 0.6 to 1 , or a concrete compressive strength ranging from 0.4 to 1 , would not significantly change the value of the ultimate shear capacity. On the other hand, increasing the span length could decrease the ultimate shear capacity, whereas the latter could increase with an additional fiber factor. As a result, the presence of these input variables was determined to be important in predicting the USCs of SFRC beams. 

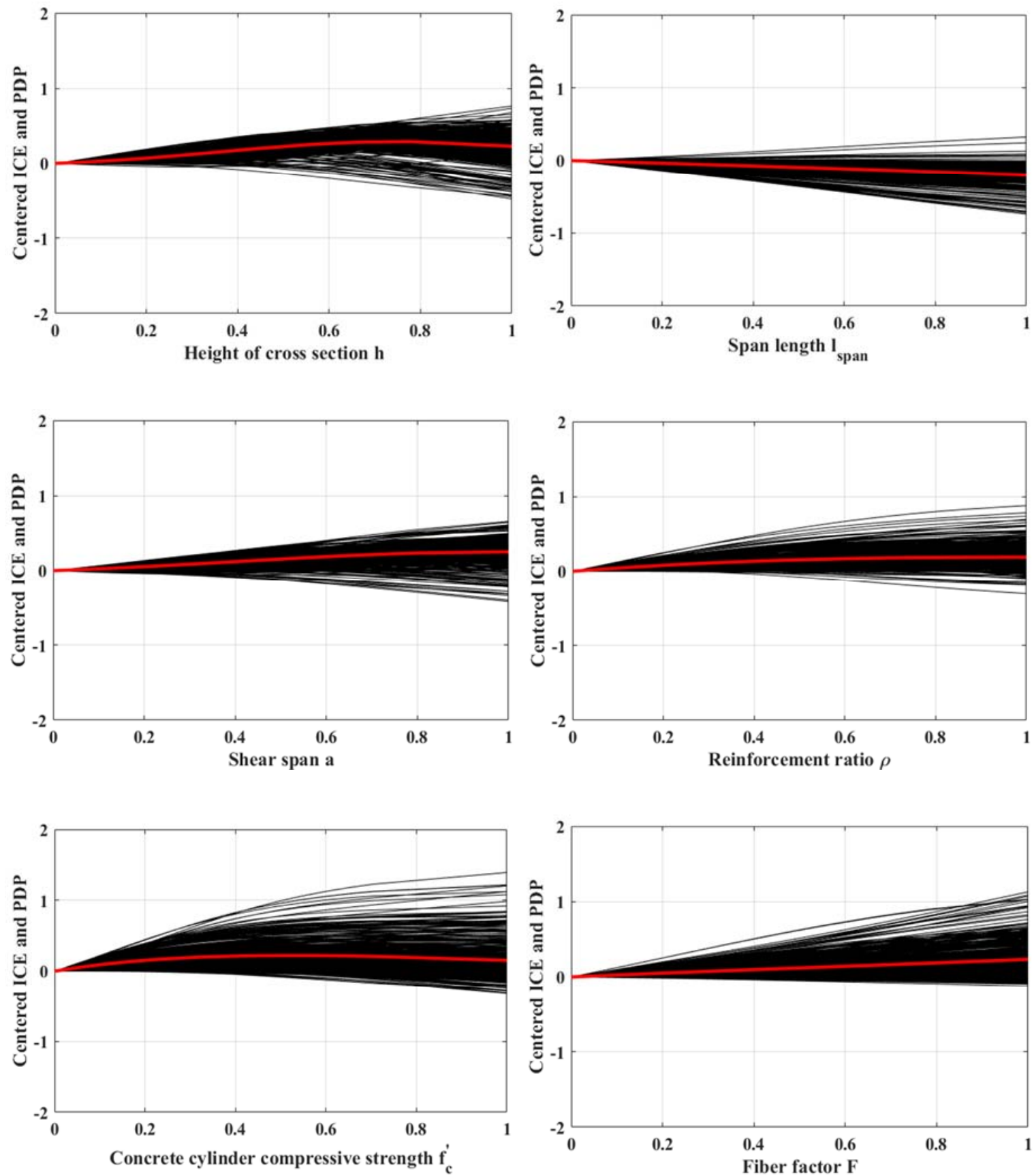

Figure 9. ICE (black lines) and PDPs (red lines) of height of cross-section, span length, shear span, reinforcement ratio, concrete compressive strength, and fiber factor obtained from the NN-RCGA model. 


\subsubsection{Very Important Factors}

As shown in Table 8 and Figure 10, clear depth ratio, web width, and effective depth are the three most important variables for predicting the USCs of SFRC beams. The maximum variation values of the latter while varying these factors were $0.7246,0.5243$, and 0.4238 , respectively. The effective depth had a linear relationship with ultimate shear capacity within the $0-0.8$ range, whereas from 0.8 to 1 the ultimate shear capacity remained almost constant, reaching a maximum value of 0.4238 . Furthermore, the web width correlated with ultimate shear capacity in a perfect, linear, and positive manner, whereas the clear depth ratio correlated with ultimate shear capacity in a linear but negative way. As a result, the presence of these input variables was determined to be crucial in predicting the USCs of SFRC beams.
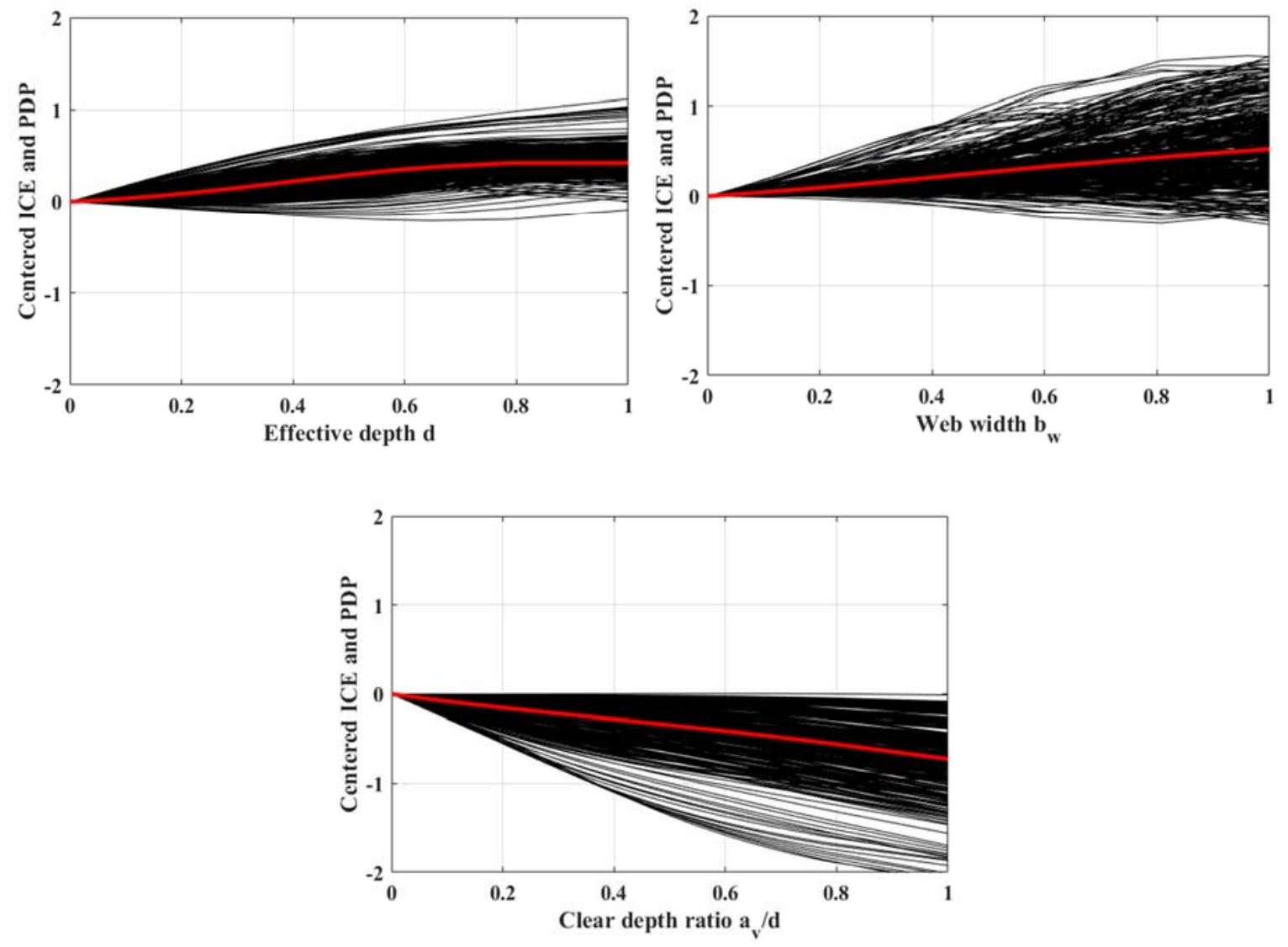

Figure 10. ICE (black lines) and PDPs (red lines) of effective depth, web width, and clear depth ratio obtained from the NN-RCGA model.

\section{Discussions}

\subsection{Dataset Used for ML Modeling}

The trustworthiness of any machine learning algorithm is dependent entirely on the reliability of the utilized database. The experimental results in this study were collected from academic journals published in Scopus or International Scientific Indexing (ISI)'s Web of Knowledge databases. In such a database, the incorporated samples should cover a wide range of values for the input variables concerned, and it is worth noting that an important number of samples in the dataset did not lead to the construction of a more accurate ML model. Indeed, similar values for input and output parameters cannot describe and reveal the behaviors of their material structures, as they do not cover a wide enough range of every possible value. A database is valuable only if it can describe the influence of all parameters on the output variable. Moreover, the precision of the data in the dataset is critical. If 
inexact values are used in the learning phase while constructing the ML algorithm, the dataset it will provide imprecise prediction values. This could lead researchers and engineers to a completely different understanding, and the study might go in the wrong direction. Therefore, in this work, an adequate amount of rigorously selected experimental data were gathered from the available literature, including 463 samples, which is to the best of our knowledge a higher number of data used for predicting the USCs of SFRC beams than any previously published work, thus enhancing the development and application of the ML models.

More importantly, most of the input variables in the present database possessed a wider range compared to those reported in the literature. As an illustration, the range of the concrete compressive strength was 9.77-215 (MPa) compared with 20.6-111.5 (MPa) in [13,164,165] or 20.6-99.9 (MPa) in [43]. The reinforcement ratio in the present database ranged from 0.37-5.72 (\%) compared with 0.9-5.72 (\%) in [164], 1.1-5.72 (\%) in [43] or 1.03-2.75 (\%) in [13]. The depth ratio was in the 0.70-6.00 range, whereas that in the work of Ahmadi et al. [13] was 1.0-6.0, and in the study of Kara et al. [165] was 2.5-5. The length to diameter ratio of fibers varied from 25.0 to 190.5 compared with 29.1-133 in [164] and $50-133$ in [165]. The fiber volume fraction in this work possessed a $0.20-4.50(\%)$ range, compared with $0.25-3.00(\%)$ in [164] and $0.25-2.00(\%)$ in [43]. Once the database contained the relevant information on the constituent materials, the prediction ML tool had the ability to estimate other experiments using the values from the training database used to construct the ML model [166]. Again, a reliable dataset that covers a wide range of input values is crucial for the development of ML models.

\subsection{Validation and Comparison of the Hybrid Models}

Validation of the hybrid models showed that both the hybrid ML models used in this study were good for predicting the USCs of SFRC beams, but that the NN-RCGA was slightly better than the NN-FFA. This is reasonable, as the NN-RCGA used the RCGA, which is robust and effective at reducing the bias and variation of the models [167]. Other published studies also confirmed the good capability of the RCGA in optimizing the parameters of the ML models $[168,169]$. A comparison of the results with previously published works (recently compiled by Lantsoght [46]) was also conducted, and is shown in Figure 11 and Table 9 (including the applications of all data). These equations are summarized in Table 10. The values gained between results obtained from the hybrid ML models and those from published works were calculated using Equation (4):

$$
\% \text { Gain }=\left\{\begin{array}{l}
\left(\left(\lambda^{N N-R C G A}-1\right)-\left(\lambda^{\text {literature }}-1\right)\right) \times 100 \text { in case of : R } \\
\left(\left(\lambda^{\text {literature }}-\lambda^{N N-R C G A}\right) / \lambda^{\text {literature }}\right) \times 100 \text { in case of }: \text { RMSE and MAE }
\end{array}\right.
$$

As shown in Table 9, the proposed ML algorithm possessed a significant improvement in performance compared with the results reported in the literature. The gain in $\mathrm{R}$ values varied from $7 \%$ to $45 \%$, whereas the gain of RMSE and MAE varied from $57.5 \%$ to $83.6 \%$ and $55.7 \%$ to $84.6 \%$, respectively. It was also found that the NN-RCGA model $(\mathrm{R}=0.9771)$ could achieve the best predictive capability for predicting the USCs of SFRC beams compared with the models in previous published works $(\mathrm{R}=0.5274-0.9075)$. This study reconfirmed that the use of hybrid ML models is more effective than traditional models. 
(a)

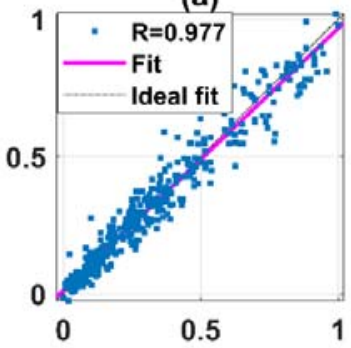

(e)

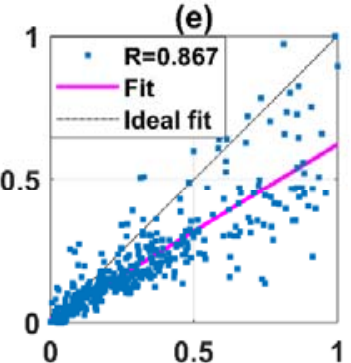

(i)

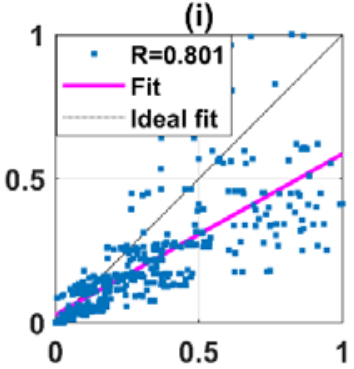

(b)

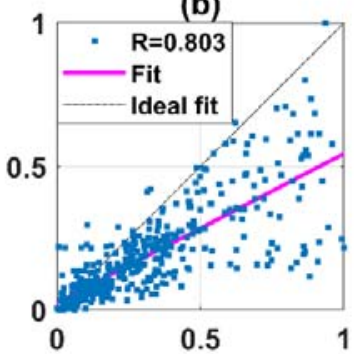

(f)

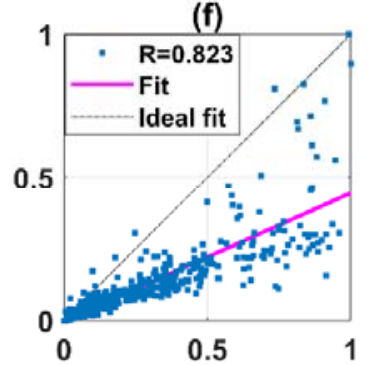

(j)

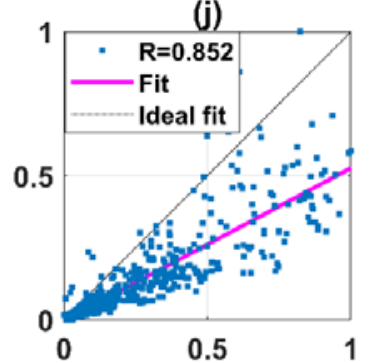

(c)

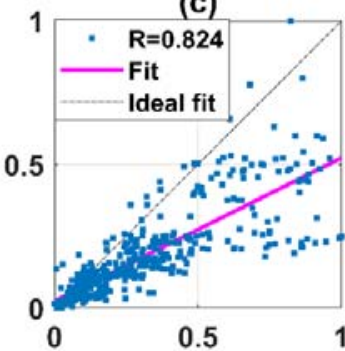

(g)

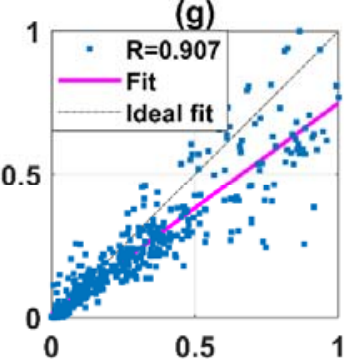

(k)

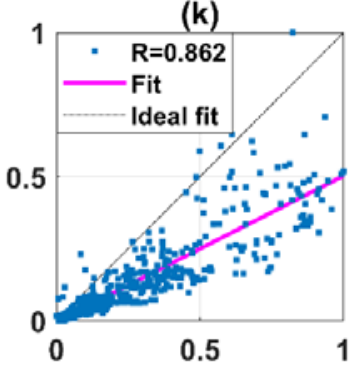

(d)

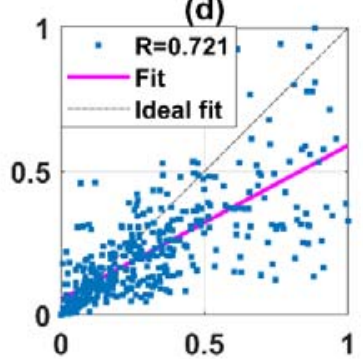

(h)

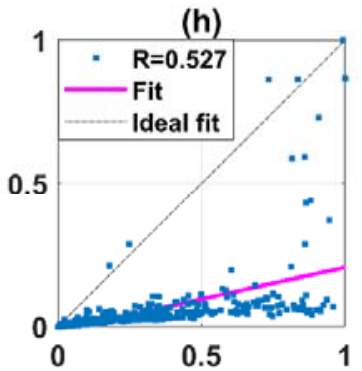

Figure 11. Regression plots using empirical equations to compare the prediction results for all data of (a) the present study using NN-RCGA with the literature: (b) Khuntia et al. [170]; (c) Sharma [98]; (d) Greenough and Nehdi [83]; (e) Ashour et al. [57] with a/d > 2.5; (f) Ashour et al. [57] with a/d < 2.5; (g) Sarveghadi et al. [171]; (h) Imam et al. [89]; (i) Ahmadi et al. [13] using Formulation 2; (j) Ahmadi et al. [13] using Formulation 3; and (k) Ahmadi et al. [13] using Formulation 4.

Table 9. Statistical measures of the predicted values against experimental ultimate shear strength.

\begin{tabular}{lcccccc}
\hline \multicolumn{1}{c}{ Method } & R & RMSE & MAE & $\begin{array}{c}\text { \% Gain: } \\
\text { R }\end{array}$ & $\begin{array}{c}\text { \% Gain: } \\
\text { RMSE }\end{array}$ & $\begin{array}{c}\text { \% Gain: } \\
\text { MAE }\end{array}$ \\
\hline NN-RCGA model & & & & - & - & - \\
Khuntia et al. [170] & 0.9771 & 0.0526 & 0.0374 & -17.5 & +72.5 & +70.1 \\
Sharma [98] & 0.8025 & 0.1911 & 0.1252 & +17.5 & +71.2 \\
Greenough and Nehdi [83] & 0.8237 & 0.1936 & 0.1299 & +15.3 & +72.8 & +69.5 \\
Ashour et al. [57] with a/d $>2.5$ & 0.7205 & 0.1897 & 0.1228 & +25.7 & +72.3 & +67.0 \\
Ashour et al. [57] with a/d $<2.5$ & 0.8672 & 0.1642 & 0.1134 & +11.0 & +68.0 & +77.4 \\
Sarveghadi et al. [171] & 0.9075 & 0.1238 & 0.0844 & +7.0 & +57.5 & +55.7 \\
Imam et al. [89] & 0.5274 & 0.3209 & 0.2423 & +45.0 & +83.6 & +84.6 \\
Ahmadi et al. [13] using & 0.8015 & 0.1809 & 0.1208 & +17.6 & +70.9 & +69.0 \\
Formulation 2 & & & & & & +15.4 \\
Ahmadi et al. [13] using & 0.8517 & 0.1994 & 0.1461 & +12.5 & +73.6 & +74.4 \\
Formulation 3 & & & & & & +74.3 \\
Ahmadi et al. [13] using & 0.8617 & 0.2049 & 0.1509 & +11.5 & +74.3 & +75.2 \\
Formulation 4 & & & & & & \\
\hline
\end{tabular}


Table 10. Table 10. Empirical equations gathered from the available literature (mostly from compilation of Lantsoght [46]).

\begin{tabular}{|c|c|}
\hline Sarveghadi et al. [171] & $\begin{array}{l}\mathrm{V}_{\mathrm{u}}=\left[\rho+\frac{\rho}{v_{\mathrm{b}}}+\frac{1}{\frac{\mathrm{a}}{\mathrm{d}}}\left(\frac{\rho \mathrm{f}_{\mathrm{t}}^{\prime}(\rho+2)\left(\mathrm{f}_{\mathrm{t}}^{\prime} \frac{\mathrm{a}}{\mathrm{d}}-\frac{3}{v_{\mathrm{b}}}\right)}{\frac{a}{\mathrm{~d}}}+\mathrm{f}_{\mathrm{t}}^{\prime}\right)+v_{\mathrm{b}}\right] \mathrm{b}_{\omega} \mathrm{d} \\
\mathrm{f}_{\mathrm{t}}^{\prime}=0.79 \sqrt{\mathrm{f}_{\mathrm{c}}^{\prime}} \\
v_{\mathrm{b}}=0.41 \tau \mathrm{F} ; \text { with } \tau=4.15(\mathrm{MPa})\end{array}$ \\
\hline Kwak et al. [101] & $\begin{array}{l}\mathrm{V}_{\mathrm{u}}=\left[3.7 \mathrm{ef}_{\mathrm{spfc}}^{2 / 3}\left(\rho \frac{\mathrm{d}}{\mathrm{a}}\right)^{1 / 3}+0.8 v_{\mathrm{b}}\right] \mathrm{b}_{\mathrm{w}} \mathrm{d} \\
\mathrm{f}_{\mathrm{spfc}}=\frac{\mathrm{f}_{\text {cuf }}}{20-\sqrt{\mathrm{F}}}+0.7+\sqrt{\mathrm{F}}(\mathrm{MPa}) \\
\mathrm{e}=\left\{\begin{array}{l}1 \text { for } \frac{\mathrm{a}}{\mathrm{d}}>3.4 \\
3.4 \frac{\mathrm{d}}{\mathrm{a}} \text { for } \frac{\mathrm{a}}{\mathrm{d}} \leq 3.4\end{array}\right.\end{array}$ \\
\hline Greenough and Nehdi [83] & $\begin{array}{l}\mathrm{V}_{\mathrm{u}}=\left[0.35\left(1+\sqrt{\frac{400}{\mathrm{~d}}}\right)\left(\mathrm{f}_{\mathrm{c}}^{\prime}\right)^{0.18}\left((1+\mathrm{F}) \rho \frac{\mathrm{d}}{\mathrm{a}}\right)^{0.4}+0.9 \eta_{\mathrm{o}} \tau \mathrm{F}\right] \mathrm{b}_{\omega} \mathrm{d} \\
\tau=4.15(\mathrm{MPa})\end{array}$ \\
\hline Khuntia et al. [170] & $\mathrm{V}_{\mathrm{u}}=\left[(0.167+0.25 \mathrm{~F}) \sqrt{\mathrm{f}_{\mathrm{c}}^{\prime}}\right] \mathrm{b}_{\omega} \mathrm{d}$ \\
\hline Sharma [98] & $\mathrm{V}_{\mathrm{u}}=\left(\frac{2}{3} \times 0.8 \sqrt{\mathrm{f}_{\mathrm{c}}^{\prime}}\left(\frac{\mathrm{d}}{\mathrm{a}}\right)^{0.25}\right) \mathrm{b}_{\omega} \mathrm{d}$ \\
\hline Mansur et al. [56] & $\begin{array}{l}\mathrm{V}_{\mathrm{u}}=\mathrm{V}_{\mathrm{c}}+\sigma_{\mathrm{tu}} \mathrm{b}_{\omega} \mathrm{d} \\
\mathrm{V}_{\mathrm{c}}=\left(0.16 \sqrt{\mathrm{f}_{\mathrm{c}}^{\prime}}+17.2 \frac{\rho \mathrm{Vd}}{\mathrm{M}}\right) \mathrm{b}_{\omega} \mathrm{d} \leq 0.29 \sqrt{\mathrm{f}_{\mathrm{c}}^{\prime}} \mathrm{b}_{\omega} \mathrm{d} \\
\sigma_{\mathrm{tu}}=3.2 \eta_{\mathrm{o}} \eta_{1} \mathrm{~F} \tau ; \text { with } \tau=2.58 \mathrm{MPa} \\
\eta_{1}=1-\frac{\tanh \left(\beta \frac{\mathrm{f}}{2}\right)}{\beta \frac{\mathrm{l}_{\mathrm{f}}}{2}} \\
\beta=\sqrt{\frac{2 \pi \mathrm{G}_{\mathrm{m}}}{\mathrm{E}_{\mathrm{f}} \mathrm{A}_{\mathrm{f}} \ln \left(\frac{\mathrm{s}}{\mathrm{r}_{\mathrm{f}}}\right)}} \\
\mathrm{S}=25 \sqrt{\frac{\mathrm{d}_{\mathrm{f}}}{\mathrm{V}_{\mathrm{f}} \mathrm{l}_{\mathrm{f}}}}\end{array}$ \\
\hline Ashour et al. [57] & $\begin{array}{l}\mathrm{V}_{\mathrm{u}}=\left[\left(0.7 \sqrt{\mathrm{f}_{\mathrm{c}}^{\prime}}+7 \mathrm{~F}\right) \frac{\mathrm{d}}{\mathrm{a}}+17.2 \rho \frac{\mathrm{d}}{\mathrm{a}}\right] \mathrm{b}_{\mathrm{\omega}} \mathrm{d} \\
\mathrm{V}_{\mathrm{u}}=\left[\left(2.11 \sqrt[3]{\mathrm{f}_{\mathrm{c}}^{\prime}}+7 \mathrm{~F}\right)\left(\rho \frac{\mathrm{d}}{\mathrm{a}}\right)^{0.333}\right] \mathrm{b}_{\omega} \mathrm{d} \text { for } \frac{\mathrm{a}}{\mathrm{d}} \geq 2.5 \\
\mathrm{~V}_{\mathrm{u}}\left[\left(\left(2.11 \sqrt[3]{\mathrm{f}_{\mathrm{c}}^{\prime}}+7 \mathrm{~F}\right)\left(\rho \frac{\mathrm{d}}{\mathrm{a}}\right)^{0.333}\right) \frac{2.5}{\frac{\mathrm{a}}{\mathrm{d}}}+v_{\mathrm{b}}\left(2.5-\frac{\mathrm{a}}{\mathrm{d}}\right)\right] \mathrm{b}_{\omega} \mathrm{d} \text { for } \frac{\mathrm{a}}{\mathrm{d}}<2.5\end{array}$ \\
\hline Arslan et al. [15] & $\begin{array}{l}\mathrm{V}_{\mathrm{u}}=\left[\left(0.2\left(\mathrm{f}_{\mathrm{c}}^{\prime}\right)^{2 / 3} \frac{\mathrm{c}}{\mathrm{d}}+\sqrt{\rho(1+4 \mathrm{~F}) \mathrm{f}_{\mathrm{c}}^{\prime}}\right) \sqrt[3]{\frac{3}{\frac{d}{d}}}\right] \mathrm{b}_{\omega} \mathrm{d} \\
\left(\frac{\mathrm{c}}{\mathrm{d}}\right)^{2}+\left(\frac{600 \rho}{\mathrm{f}_{\mathrm{c}}^{\prime}}\right)\left(\frac{\mathrm{c}}{\mathrm{d}}\right)-\frac{600 \rho}{\mathrm{f}_{\mathrm{c}}^{\prime}}=0\end{array}$ \\
\hline Imam et al. [89] & $\begin{array}{l}\mathrm{V}_{\mathrm{u}}=\left[0.6 \psi \sqrt[3]{\omega}\left(\left(\mathrm{f}_{\mathrm{c}}^{\prime}\right)^{0.44}+275 \sqrt{\frac{\omega}{\left(\frac{\mathrm{a}}{\mathrm{d}}\right)^{5}}}\right)\right] \mathrm{b}_{\omega} \mathrm{d} \\
\psi=\frac{1+\sqrt{\frac{5.08}{\mathrm{da}_{\mathrm{a}}}}}{\sqrt{1+\frac{\mathrm{d}}{25 \mathrm{~d}_{\mathrm{a}}}}} \\
\omega=\rho(1+4 \mathrm{~F})\end{array}$ \\
\hline Yakoub [172] & 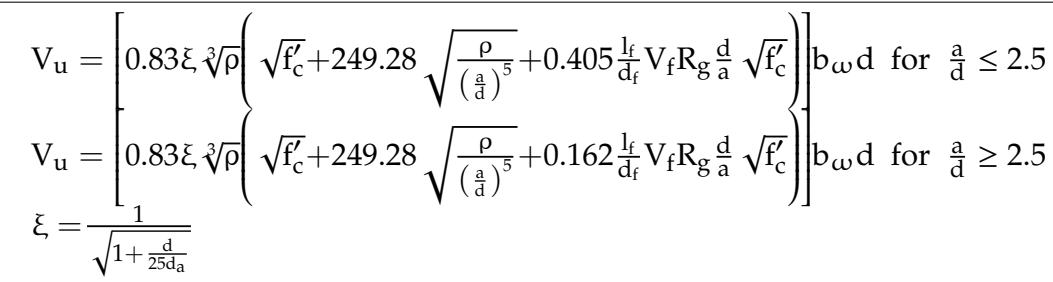 \\
\hline Ahmadi et al. [13] & $\begin{array}{l}\mathrm{V}_{\mathrm{u}}=\frac{\mathrm{d}}{\mathrm{a}}\left(\frac{\mathrm{F}}{\mathrm{d}}+0.555 \sqrt{\rho \mathrm{f}_{\mathrm{c}}^{\prime}}+1\right)+1 \\
\mathrm{~V}_{\mathrm{u}}=\rho-\frac{37.957 \frac{\mathrm{a}}{\mathrm{d}} \rho}{\mathrm{d}+\mathrm{F}-10.57}+\frac{\mathrm{d}+\left(\mathrm{f}_{\mathrm{c}}^{\prime}\right)^{2}}{9.44 \frac{\mathrm{a}}{\mathrm{d}} \mathrm{f}_{\mathrm{c}}^{\prime}} \\
\mathrm{V}_{\mathrm{u}}=0.095 \frac{\mathrm{f}_{\mathrm{c}}^{\prime}}{\frac{\mathrm{a}}{\mathrm{d}}}+\frac{\rho-0.137}{\frac{\mathrm{a}}{\mathrm{d}}-0.395}+\frac{0.108 \mathrm{~d}+\mathrm{F}}{\mathrm{f}_{\mathrm{c}}^{\prime}-\frac{\mathrm{a}}{\mathrm{d}}+85.256}\end{array}$ \\
\hline
\end{tabular}




\subsection{Importance of Selection of the Input Factors}

Many studies have showed that the post-cracking tensile strength of fiber-reinforced concrete is an important factor, which is represented by a significant reserve strength in the case of fiber-reinforced concrete beams failing in shear after the first diagonal cracking appears [165]. In the work of Khuntia et al. [170], the authors suggested that the dependence of such post-cracking tensile stress on many factors, including volume fraction, shape, aspect ratio, and the surface characteristics of the fibers, as well as the mechanical properties of concrete. In addition, the type of concrete (i.e., normal or lightweight) and steel fibers was taken into account when using empirical equations. However, in the current work, the type of fibers and concrete have not been taken as input parameters. With the satisfactory precision of the predictive NN-RCGA model, it can be concluded that these input variables would have no significant effect in predicting the USCs of SFRC beams. In the present work, the dataset containing 16 input variables could exhaustively represent all the factors affecting the ultimate shear capacity of steel fiber-reinforced concrete beams. For the sake of comparison, Kara et al. [165] only considered five factors as input variables, and Adhikary and Mutsuyoshi [43] compared the accuracy of the proposed $\mathrm{NN}$ algorithms for cases using four and five factors as input variables.

Predicting the USC of SFRC is a difficult task, as the relationship between the constituents and the target is highly nonlinear. Several current codes, guidelines, and studies have proposed some empirical prediction equations. The appearance of any factor in such empirical equations could demonstrate the importance of that factor in predicting the USC. In a series of works by Sarveghadi et al. [171], Kwak et al. [101], Ashour et al. [57], and Ahmadi et al. [13], factors such as the reinforcement ratio, fiber factor, shear span, effective depth, concrete compressive strength, and web width are considered. Several additions apart from the above factors have also been observed in the works of Arslan et al. [15], Imam et al. [89], and Greenough and Nehdi [83]. The height of the compression zone, the maximum aggregate size, and the fiber orientation factor (a value of 0.41 is assumed) have been considered. Furthermore, Khuntia et al. [170] removed shear span in the proposed empirical formulation, and Sharma [98] removed the fiber factor (which includes the diameter, length, and volume percentage of steel fibers), to predict the ultimate shear capacity of the concrete beams. On the other hand, Mansur et al. [56] added the fiber orientation factor, length factor, sectional shear force, and sectional moment to predict the ultimate shear capacity. Last but not least, Yakoub [172] added the fiber volume fraction and, in particular, the fiber geometry factor, to estimate the ultimate shear capacity.

Overall, it is interesting to observe that the sensitivity analysis using ICE and PDPs in the present study could also demonstrate the importance of these factors. The effective depth and web width were found to be the most affecting factors to the prediction tool, as can be determined from the empirical equations (Table 10). The clear shear span to effective depth ratio was also be found more influential than the shear span to effective depth ratio [173]. The finding of this work that shear span, height of cross-section, fiber factor, concrete cylinder compressive strength, span length, and reinforcement ratio are all important variables is in good agreement with the literature mentioned above.

\section{Conclusions}

In this study, two hybrid ML model—namely, NN-RCGA and NN-FFA—were developed and applied for predicting the USCs of SFRC beams. The NN-RCGA and NN-FFA are a combination of a NN and two nature-inspired optimization techniques, namely the RCGA and the FFA, respectively. A database of 463 experimental data, including input variables (geometry of the beam, concrete mixture, and fiber information) and an output variable (USCs of SFRC beams) was constructed from the data collected in published works. Using several statistical criteria such as R, RMSE, and MAE, the predictive capabilities of the proposed hybrid algorithms were validated and compared for both a training (70\% data) and a testing ( $30 \%$ remaining data) dataset. Furthermore, sensitivity analysis was also carried out using ICE and PDP to evaluate the importance of input variables. 
The results showed that the NN-RCGA $(\mathrm{R}=0.9771)$ was better than the NN-FFA and other previously published models $(\mathrm{R}=0.5274-0.9075)$ in predicting the USCs of SFRC beams. Thus, it can be reasonably concluded that the NN-RCGA is a promising tool and method for more accurately predicting the USCs of SFRC beams. The sensitivity analysis showed that web width and effective depth were the most important factors positively influencing beam shear capacity. They were considered to be the most critical parameters in modeling the shear capacities of SFRC beams. Removal of unimportant factors found in this study should be investigated and carried out in further study to improve the capabilities of the ML models to predict the USCs of SFRC beams. Several prospective works following this study will pave the way for a more comprehensive knowledge concerning reinforced concrete beams, including (i) the gathering of more reliable data of general reinforced concrete beams to verify the possibility of using ML algorithms to predict the USCs of reinforced concrete beams; (ii) considering more behaviors of SFRC beams, such as structural behaviors during failure.

The results of this study might help to permit quick and accurate assessments of the shear capacities of SFRC beams for practical engineering purposes. As a consequence, a Matlab function (.m file) using a pre-trained NN-RCGA algorithm (containing the NN-RCGA network used in this study, named as "net") and the testing dataset (.xlsx file) are given in Supplementary Materials. This function predicts the USCs of SFRC beams using 16 input variables.

Supplementary Materials: The following are available online at http://www.mdpi.com/2071-1050/12/7/2709/s1. All Supplementary Materials are appended to this paper.

Author Contributions: Conceptualization, T.-T.L. and H.-B.L.; methodology, L.M.L.; software, V.Q.T.; validation, H.-L.T.V., V.Q.T. and H.-B.L.; formal analysis, H.-B.L.; investigation, L.M.L.; resources, T.-T.L.; data curation, T.-T.L.; writing—original draft preparation, V.Q.T., H.-L.T.V.; writing—review and editing, H.-B.L.; visualization, T.-T.L.; supervision, B.T.P.; project administration, B.T.P.; funding acquisition, H.-B.L. All authors have read and agreed to the published version of the manuscript.

Funding: This research received no external funding.

Conflicts of Interest: The authors declare no conflict of interest.

\section{References}

1. Dao, D.V.; Ly, H.-B.; Trinh, S.H.; Le, T.-T.; Pham, B.T. Artificial Intelligence Approaches for Prediction of Compressive Strength of Geopolymer Concrete. Materials (Basel) 2019, 12, 983. [CrossRef] [PubMed]

2. Tran, V.Q.; Nguyen, H.L.; Dao, V.D.; Hilloulin, B.; Nguyen, L.K.; Nguyen, Q.H.; Le, T.-T.; Ly, H.-B. Temperature effects on chloride binding capacity of cementitious materials. Mag. Concr. Res. 2019, 1-39. [CrossRef]

3. Dao, D.V.; Adeli, H.; Ly, H.-B.; Le, L.M.; Le, V.M.; Le, T.-T.; Pham, B.T. A Sensitivity and Robustness Analysis of GPR and ANN for High-Performance Concrete Compressive Strength Prediction Using a Monte Carlo Simulation. Sustainability 2020, 12, 830. [CrossRef]

4. Lantsoght, E.O.L. How do steel fibers improve the shear capacity of reinforced concrete beams without stirrups? Compos. Part B Eng. 2019, 175, 107079. [CrossRef]

5. Mashhadban, H.; Kutanaei, S.S.; Sayarinejad, M.A. Prediction and modeling of mechanical properties in fiber reinforced self-compacting concrete using particle swarm optimization algorithm and artificial neural network. Constr. Build. Mater. 2016, 119, 277-287. [CrossRef]

6. Yazıcı, S..; İnan, G.; Tabak, V. Effect of aspect ratio and volume fraction of steel fiber on the mechanical properties of SFRC. Constr. Build. Mater. 2007, 21, 1250-1253. [CrossRef]

7. Ferrara, L.; Meda, A. Relationships between fibre distribution, workability and the mechanical properties of SFRC applied to precast roof elements. Mater. Struct. 2006, 39, 411-420. [CrossRef]

8. Özcan, D.M.; Bayraktar, A.; Şahin, A.; Haktanir, T.; Türker, T. Experimental and finite element analysis on the steel fiber-reinforced concrete (SFRC) beams ultimate behavior. Constr. Build. Mater. 2009, 23, 1064-1077. [CrossRef]

9. Higashiyama, H.; Ota, A.; Mizukoshi, M. Design Equation for Punching Shear Capacity of SFRC Slabs. Int. J. Concr. Struct. Mater. 2011, 5, 35-42. [CrossRef]

10. Gandomi, A.; Alavi, A.; Yun, G. Nonlinear modeling of shear strength of SFRC beams using linear genetic programming. Struct. Eng. Mech. 2011, 38, 1-25. [CrossRef] 
11. Pansuk, W.; Nguyen, T.N.; Sato, Y.; Den Uijl, J.A.; Walraven, J.C. Shear capacity of high performance fiber reinforced concrete I-beams. Constr. Build. Mater. 2017, 157, 182-193. [CrossRef]

12. Bae, B.-I.; Choi, H.-K.; Choi, C.-S. Flexural and shear capacity evaluation of reinforced ultra-high strength concrete members with steel rebars. Key Eng. Mater. 2014, 577-578, 17-20.

13. Ahmadi, M.; Kheyroddin, A.; Dalvand, A.; Kioumarsi, M. New empirical approach for determining nominal shear capacity of steel fiber reinforced concrete beams. Constr. Build. Mater. 2020, 234, 117293. [CrossRef]

14. Nino, S.; Piero, C.; Antonino, R. Simple Plastic Model for Shear Critical SFRC Beams. J. Struct. Eng. 2010, 136, 390-400.

15. Arslan, G. Shear strength of Steel Fiber Reinforced Concrete (SFRC) slender beams. KSCE J. Civ. Eng. 2014, 18, 587-594. [CrossRef]

16. Hanai, J.B.D.; Holanda, K.M.A. Similarities between punching and shear strength of steel fiber reinforced concrete (SFRC) slabs and beams. Revista IBRACON de Estruturas e Materiais 2008, 1, 1-16. [CrossRef]

17. Ly, H.-B.; Desceliers, C.; Le, L.M.; Le, T.-T.; Pham, B.T.; Nguyen-Ngoc, L.; Doan, V.T.; Le, M. Quantification of Uncertainties on the Critical Buckling Load of Columns under Axial Compression with Uncertain Random Materials. Materials 2019, 12, 1828. [CrossRef]

18. Ly, H.-B.; Le, T.-T.; Le, L.M.; Tran, V.Q.; Le, V.M.; Vu, H.-L.T.; Nguyen, Q.H.; Pham, B.T. Development of Hybrid Machine Learning Models for Predicting the Critical Buckling Load of I-Shaped Cellular Beams. Appl. Sci. 2019, 9, 5458. [CrossRef]

19. Ly, H.-B.; Monteiro, E.; Le, T.-T.; Le, V.M.; Dal, M.; Regnier, G.; Pham, B.T. Prediction and Sensitivity Analysis of Bubble Dissolution Time in 3D Selective Laser Sintering Using Ensemble Decision Trees. Materials 2019, 12, 1544. [CrossRef]

20. Ly, H.-B.; Pham, B.T.; Dao, D.V.; Le, V.M.; Le, L.M.; Le, T.-T. Improvement of ANFIS Model for Prediction of Compressive Strength of Manufactured Sand Concrete. Appl. Sci. 2019, 9, 3841. [CrossRef]

21. Ly, H.-B.; Le, L.M.; Phi, L.V.; Phan, V.-H.; Tran, V.Q.; Pham, B.T.; Le, T.-T.; Derrible, S. Development of an AI Model to Measure Traffic Air Pollution from Multisensor and Weather Data. Sensors 2019, $19,4941$. [CrossRef] [PubMed]

22. Nguyen, H.-L.; Pham, B.T.; Son, L.H.; Thang, N.T.; Ly, H.-B.; Le, T.-T.; Ho, L.S.; Le, T.-H.; Tien Bui, D. Adaptive Network Based Fuzzy Inference System with Meta-Heuristic Optimizations for International Roughness Index Prediction. Appl. Sci. 2019, 9, 4715. [CrossRef]

23. Nguyen, H.-L.; Le, T.-H.; Pham, C.-T.; Le, T.-T.; Ho, L.S.; Le, V.M.; Pham, B.T.; Ly, H.-B. Development of Hybrid Artificial Intelligence Approaches and a Support Vector Machine Algorithm for Predicting the Marshall Parameters of Stone Matrix Asphalt. Appl. Sci. 2019, 9, 3172. [CrossRef]

24. Pham, B.T.; Nguyen, M.D.; Dao, D.V.; Prakash, I.; Ly, H.-B.; Le, T.-T.; Ho, L.S.; Nguyen, K.T.; Ngo, T.Q.; Hoang, V.; et al. Development of artificial intelligence models for the prediction of Compression Coefficient of soil: An application of Monte Carlo sensitivity analysis. Sci. Total Environ. 2019, 679, 172-184. [CrossRef]

25. Qi, C.; Ly, H.-B.; Chen, Q.; Le, T.-T.; Le, V.M.; Pham, B.T. Flocculation-dewatering prediction of fine mineral tailings using a hybrid machine learning approach. Chemosphere 2019, 125450. [CrossRef]

26. Asteris, P.G.; Armaghani, D.J.; Hatzigeorgiou, G.D.; Karayannis, C.G.; Pilakoutas, K. Predicting the shear strength of reinforced concrete beams using Artificial Neural Networks. Comput. Concr. 2019, 24, 469-488.

27. Armaghani, D.J.; Hatzigeorgiou, G.D.; Karamani, C.; Skentou, A.; Zoumpoulaki, I.; Asteris, P.G. Soft computing-based techniques for concrete beams shear strength. Procedia Struct. Integr. 2019, 17, 924-933. [CrossRef]

28. Sun, D.; Lonbani, M.; Askarian, B.; Jahed Armaghani, D.; Tarinejad, R.; Thai Pham, B.; Huynh, V.V. Investigating the Applications of Machine Learning Techniques to Predict the Rock Brittleness Index. Appl. Sci. 2020, 10, 1691. [CrossRef]

29. Huang, L.; Asteris, P.G.; Koopialipoor, M.; Armaghani, D.J.; Tahir, M.M. Invasive Weed Optimization Technique-Based ANN to the Prediction of Rock Tensile Strength. Appl. Sci. 2019, 9, 5372. [CrossRef]

30. Hajihassani, M.; Abdullah, S.S.; Asteris, P.G.; Armaghani, D.J. A gene expression programming model for predicting tunnel convergence. Appl. Sci. 2019, 9, 4650. [CrossRef]

31. Xu, H.; Zhou, J.; G. Asteris, P.; Jahed Armaghani, D.; Tahir, M.M. Supervised Machine Learning Techniques to the Prediction of Tunnel Boring Machine Penetration Rate. Appl. Sci. 2019, 9, 3715. [CrossRef]

32. Kiani, J.; Camp, C.; Pezeshk, S. On the application of machine learning techniques to derive seismic fragility curves. Comput. Struct. 2019, 218, 108-122. [CrossRef] 
33. Mangalathu, S.; Hwang, S.-H.; Choi, E.; Jeon, J.-S. Rapid seismic damage evaluation of bridge portfolios using machine learning techniques. Eng. Struct. 2019, 201, 109785. [CrossRef]

34. Mangalathu, S.; Heo, G.; Jeon, J.-S. Artificial neural network based multi-dimensional fragility development of skewed concrete bridge classes. Eng. Struct. 2018, 162, 166-176. [CrossRef]

35. Mangalathu, S.; Jeon, J.-S. Machine Learning-Based Failure Mode Recognition of Circular Reinforced Concrete Bridge Columns: Comparative Study. J. Struct. Eng. 2019, 145, 04019104. [CrossRef]

36. Mangalathu, S.; Jeon, J.-S. Classification of failure mode and prediction of shear strength for reinforced concrete beam-column joints using machine learning techniques. Eng. Struct. 2018, 160, 85-94. [CrossRef]

37. Pedroni, N.; Zio, E.; Apostolakis, G.E. Comparison of bootstrapped artificial neural networks and quadratic response surfaces for the estimation of the functional failure probability of a thermal-hydraulic passive system. Reliab. Eng. Syst. Saf. 2010, 95, 386-395. [CrossRef]

38. Ricotti, M.E.; Zio, E. Neural network approach to sensitivity and uncertainty analysis. Reliab. Eng. Syst. Saf. 1999, 64, 59-71. [CrossRef]

39. Ak, R.; Li, Y.; Vitelli, V.; Zio, E.; López Droguett, E.; Magno Couto Jacinto, C. NSGA-II-trained neural network approach to the estimation of prediction intervals of scale deposition rate in oil \& gas equipment. Expert Syst. Appl. 2013, 40, 1205-1212.

40. Ly, H.-B.; Le, L.M.; Duong, H.T.; Nguyen, T.C.; Pham, T.A.; Le, T.-T.; Le, V.M.; Nguyen-Ngoc, L.; Pham, B.T. Hybrid Artificial Intelligence Approaches for Predicting Critical Buckling Load of Structural Members under Compression Considering the Influence of Initial Geometric Imperfections. Appl. Sci. 2019, 9, 2258. [CrossRef]

41. Le, L.M.; Ly, H.-B.; Pham, B.T.; Le, V.M.; Pham, T.A.; Nguyen, D.-H.; Tran, X.-T.; Le, T.-T. Hybrid Artificial Intelligence Approaches for Predicting Buckling Damage of Steel Columns Under Axial Compression. Materials 2019, 12, 1670. [CrossRef] [PubMed]

42. Dao, D.V.; Trinh, S.H.; Ly, H.-B.; Pham, B.T. Prediction of Compressive Strength of Geopolymer Concrete Using Entirely Steel Slag Aggregates: Novel Hybrid Artificial Intelligence Approaches. Appl. Sci. 2019, 9, 1113. [CrossRef]

43. Adhikary, B.B.; Mutsuyoshi, H. Prediction of shear strength of steel fiber RC beams using neural networks. Constr. Build. Mater. 2006, 20, 801-811. [CrossRef]

44. Angeline, P.J. Genetic Programming: On the Programming of Computers by Means of Natural Selection; Koza, J.R., Ed.; A Bradford Book, MIT Press: Cambridge, MA, USA, 1992; ISBN 0-262-11170-5. xiv + 819pp.

45. Yaseen, Z.M.; Tran, M.T.; Kim, S.; Bakhshpoori, T.; Deo, R.C. Shear strength prediction of steel fiber reinforced concrete beam using hybrid intelligence models: A new approach. Eng. Struct. 2018, 177, 244-255. [CrossRef]

46. Abdul-Zaher, A.S.; Abdul-Hafez, L.M.; Tawfic, Y.R.; Hammed, O. Shear behavior of fiber reinforced concrete beams. J. Eng. Sci. Assiut Univ. 2016, 44, 132-144.

47. Li, V.C.; Ward, R.; Hamza, A.M. Steel and synthetic fibers as shear reinforcement. ACI Mater. J. 1992, 89, 499-508.

48. Adebar, P.; Mindess, S.; St.-Pierre, D.; Olund, B. Shear tests of fiber concrete beams without stirrups. ACI Struct. J. 1997, 94, 68-76.

49. Lim, D.H.; Oh, B.H. Experimental and theoretical investigation on the shear of steel fibre reinforced concrete beams. Eng. Struct. 1999, 21, 937-944. [CrossRef]

50. Amin, A.; Foster, S.J. Shear strength of steel fibre reinforced concrete beams with stirrups. Eng. Struct. 2016, 111, 323-332. [CrossRef]

51. Lim, T.Y.; Paramasivam, P.; Lee, S.L. Analytical Model for Tensile Behavior of Steel-Fiber Concrete. ACI Mater. J. 1987, 84, 286-298.

52. Aoude, H.; Cohen, M. Shear response of SFRC beams constructed with SCC and steel fibers. Electron. J. Struct. Eng. 2014, 14, 71-83.

53. Araújo, D.L.; Nunes, F.G.T.; Toledo Filho, R.D.; de Andrade, M.A.S. Shear strength of steel fiber-reinforced concrete beams [Resistência ao cisalhamento de vigas de concreto reforçado com fibras de aço]. Acta Sci. Technol. 2014, 36, 389-397. [CrossRef]

54. Aoude, H.; Belghiti, M.; Cook, W.D.; Mitchell, D. Response of steel fiber-reinforced concrete beams with and without stirrups. ACI Struct. J. 2012, 109, 359-367.

55. Manju, R.; Sathya, S.; Sylviya, B. Shear strength of high - Strength steel fibre reinforced concrete rectangular beams. Int. J. Civ. Eng. Technol. 2017, 8, 1716-1729. 
56. Mansur, M.A.; Ong, K.C.G.; Paramasivam, P. Shear strength of fibrous concrete beams without stirrups. J. Struct. Eng. 1986, 112, 2066-2079. [CrossRef]

57. Ashour, S.A.; Hasanain, G.S.; Wafa, F.F. Shear behavior of high-strength fiber reinforced concrete beams. ACI Struct. J. 1992, 89, 176-184.

58. Minelli, F.; Plizzari, G.A. On the effectiveness of steel fibers as shear reinforcement. ACI Struct. J. 2013, 110, 379-389.

59. Narayanan, R.; Darwish, I.Y.S. Use of Steel Fibers as Shear Reinforcement. ACI Struct. J. 1987, 84, $216-227$.

60. Batson, G.; Jenkins, E.; Spatney, R. Steel fibers as shear reinforcement in beams. ACI J. 1972, 69, 640-644.

61. Noghabai, K. Beams of fibrous concrete in shear and bending: Experiment and model. J. Struct. Eng. N. Y. 2000, 126, 243-251. [CrossRef]

62. Casanova, P.; Rossi, P. Shear Strength of Fiber Reinforced Concrete Beams without Stirrups. In Structural Applications of Fiber Reinforced Concrete, SP-182; American Concrete Institute: Farmington Hills, MI, USA, 1999; pp. 53-67.

63. Casanova, P.; Rossi, P.; Schaller, I. Can steel fibers replace transverse reinforcements in reinforced concrete beams? ACI Mater. J. 1997, 94, 341-354.

64. Para-Montesinos, G.; Wight, J.K.; Dinh, H.; Libbrecht, A.; Padilla, C. Shear Strength of Fiber Reinforced Concrete Beams without Stirrups; University of Michigan: Ann Arbor, MI, USA, 2006; p. 39.

65. Chalioris, C.E.; Sfiri, E. Shear performance of steel fibrous concrete beams. Procedia Eng. 2011, 14, $2064-2068$. [CrossRef]

66. Qissab, M.A.; Salman, M.M. Shear strength of non-prismatic steel fiber reinforced concrete beams without stirrups. Struct. Eng. Mech. 2018, 67, 347-358. [CrossRef]

67. Cho, S.-H.; Kim, Y.-I. Effects of steel fibers on short beams loaded in shear. ACI Struct. J. 2003, 100, 765-774.

68. Randl, N.; Mészöly, T.; Harsányi, P. Shear behaviour of UHPC beams with varying degrees of fibre and shear reinforcement. In Proceedings of the Fib Symposium 2017, Maastricht, The Netherlands, 12-14 June 2017; pp. 500-507.

69. Mohammed-Saeed, M.; Aoude, H. Shear behavior of SFRC and SCFRC beams. In Proceedings of the Proceedings, Annual Conference - Canadian Society for Civil Engineering, University of Ottawa, Ottawa, ON, Canada, 6-9 June 2012; Volume 3, pp. 2557-2566.

70. Roberts, T.; Ho, N. Shear failure of deep fibre reinforced concrete beams. Int. J. Cem. Compos. Light. Concr. 1982, 4, 145-152. [CrossRef]

71. Cucchiara, C.; La Mendola, L.; Papia, M. Effectiveness of stirrups and steel fibres as shear reinforcement. Cem. Concr. Compos. 2004, 26, 777-786. [CrossRef]

72. Rosenbusch, J.; Teutsch, M. Trial Beams in Shear Brite/Euram Project 97-4163 Final Report Sub Task 4.2; Technical University of Braunschweig: Braunschweig, Germany, 2003; pp. 105-117.

73. Dancygier, A.N.; Savir, Z. Effects of steel fibers on shear behavior of high-strength reinforced concrete beams. Adv. Struct. Eng. 2011, 14, 745-761. [CrossRef]

74. Sahoo, D.R.; Sharma, A. Effect of steel fiber content on behavior of concrete beams with and without stirrups. ACI Struct. J. 2014, 111, 1157-1166. [CrossRef]

75. Dinh, H.H.; Parra-Montesinos, G.J.; Wight, J.K. Shear behavior of steel fiber-reinforced concrete beams without stirrup reinforcement. ACI Struct. J. 2010, 107, 597-606.

76. Sahoo, D.R.; Bhagat, S.; Reddy, T.C.V. Experimental study on shear-span to effective-depth ratio of steel fiber reinforced concrete T-beams. Mater. Struct. 2015, 49, 3815-3830. [CrossRef]

77. Dupont, D.; Vandewalle, L. Shear capacity of concrete beams containing longitudinal reinforcement and steel fibers. ACI Spec. Publ. 2003, 216, 79-94.

78. Shoaib, A. Shear in steel fiber reinforced concrete members without stirrups. Ph.D. Thesis, Department of Civil and Environmental Engineering, University of Alberta, Alberta, Canada, 2012.

79. Furlan, S., Jr.; De Hanai, J.B. Shear behaviour of fiber reinforced concrete beams. Cem. Concr. Composites 1997, 19, 359-366. [CrossRef]

80. Shoaib, A.; Lubell, A.S.; Bindiganavile, V.S. Shear response of lightweight steel fiber reinforced concrete members without stirrups. Mater. Struct. Mater. Constr. 2015, 48, 3141-3157. [CrossRef]

81. Gali, S.; Subramaniam, K.V.L. Shear behavior of steel fiber reinforced concrete using full-field displacements from digital image correlation. In Proceedings of the MATEC Web of Conferences, University of Sharjah, Sharjah, United Arab Emirates, 18-20 April 2017; Volume 120. 
82. Singh, B.; Jain, K. An appraisal of steel fibers as minimum shear reinforcement in concrete beams. ACI Struct. J. 2014, 111, 1191-1202. [CrossRef]

83. Greenough, T.; Nehdi, M. Shear behavior of fiber-reinforced self-consolidating concrete slender beams. ACI Mater. J. 2008, 105, 468-477.

84. Spinella, N. Shear strength of full-scale steel fibre-reinforced concrete beams without stirrups. Comput. Concr. 2013, 11, 365-382. [CrossRef]

85. Huang, C.-K.; Zhang, H.Z.; Guan, Z.G. Experimental study on shear resistance of steel fiber reinforced high-strength concrete beam. ACI Spec. Publ. 2005, 228, 687-704.

86. Swamy, R.N.; Bahia, H.M. Effectiveness of steel fibers as shear reinforcement. Concr. Int. 1985, 7, 35-40.

87. Hwang, J.-H.; Lee, D.H.; Kim, K.S.; Ju, H.; Seo, S.-Y. Evaluation of shear performance of steel fibre reinforced concrete beams using a modified smeared-truss model. Mag. Concr. Res. 2013, 65, 283-296. [CrossRef]

88. Swamy, R.N.; Jones, R.; Chiam, A.T.P. Influence of steel fibers on the shear resistance of lightweight concrete I- beams. ACI Struct. J. 1993, 90, 103-114.

89. Imam, M.; Vandewalle, L.; Mortelmans, F. Shear capacity of steel fiber high-strength concrete beams. ACI Spec. Pub. 1994, 149, 227-242.

90. Tahenni, T.; Chemrouk, M.; Lecompte, T. Effect of steel fibers on the shear behavior of high strength concrete beams. Constr. Build. Mater. 2016, 105, 14-28. [CrossRef]

91. Jindal, R.L. Shear and Moment Capacities of Steel Fiber Reinforced Concrete Beams; American Concrete Institute, Publication SP: Farmington Hills, MI, USA, 1984; pp. 1-16.

92. Tan, K.H.; Murugappan, K.; Paramasivam, P. Shear behavior of steel fiber reinforced concrete beams. ACI Struct. J. 1993, 90, 3-11.

93. Kang, T.H.-K.; Kim, W.; Kwak, Y.-K.; Hong, S.-G. Shear testing of steel fiber-reinforced lightweight concrete beams without web reinforcement. ACI Struct. J. 2011, 108, 553-561.

94. Zamanzadeh, Z.; Lourenço, L.; Barros, J. Recycled steel fibre reinforced concrete failing in bending and in shear. Constr. Build. Mater. 2015, 85, 195-207. [CrossRef]

95. Kang, T.H.-K.; Kim, W.; Massone, L.M.; Galleguillos, T.A. Shear-flexure coupling behavior of steel fiber-reinforced concrete beams. ACI Struct. J. 2012, 109, 435-444.

96. Zarrinpour, M.R.; Chao, S.-H. Shear strength enhancement mechanisms of steel fiber-reinforced concrete slender beams. ACI Struct. J. 2017, 114, 729-742. [CrossRef]

97. Kim, C.-G.; Lee, H.; Park, H.-G.; Hong, G.-H.; Kang, S.-M. Effect of steel fibers on minimum shear reinforcement of high-strength concrete beams. ACI Struct. J. 2017, 114, 1109-1119. [CrossRef]

98. Sharma, A.K. Shear strength of steel fiber reinforced concrete beams. J. Am. Concr. Inst. 1986, 83, 624-628.

99. Krassowska, J.; Kosior-Kazberuk, M. Failure mode in shear of steel fiber reinforced concrete beams. In Proceedings of the MATEC Web Conference, Cape Town, South Africa, 24-26 September 2018; Volume 163. [CrossRef]

100. Shin, S.W.; Oh, J.; Ghosh, S.K. Shear behavior of laboratory-sized high-strength concrete beams reinforced with bars and steel fibers. Fiber Reinf. Concr. Dev. Innov. 1994, 142, 181-200.

101. Kwak, Y.-K.; Eberhard, M.O.; Kim, W.-S.; Kim, J. Shear strength of steel fiber-reinforced concrete beams without stirrups. ACI Struct. J. 2002, 99, 530-538.

102. Zhao, J.; Liang, J.; Chu, L.; Shen, F. Experimental study on shear behavior of steel fiber reinforced concrete beams with high-strength reinforcement. Materials 2018, 11, 1682. [CrossRef] [PubMed]

103. Kwak, K.-H.; Suh, J.; Hsu, C.-T.T. Shear-fatigue behaviour of steel fiber reinforced concrete beams. ACI Struct. J. 1991, 88, 155-160.

104. Adeli, H. Neural networks in civil engineering: 1989-2000. Comput. Civ. Infrastruct. Eng. 2001, 16, $126-142$. [CrossRef]

105. Tu, J. Advantages and disadvantages of using artificial neural networks versus logistic regression for predicting medical outcomes. J. Clin. Epidemiol. 1996, 49, 1225-1231. [CrossRef]

106. Bayat, M.; Ghorbanpour, M.; Zare, R.; Jaafari, A.; Thai Pham, B. Application of artificial neural networks for predicting tree survival and mortality in the Hyrcanian forest of Iran. Comput. Electron. Agric. 2019, 164, 104929. [CrossRef] 
107. Pham, B.T.; Nguyen, M.D.; Ly, H.-B.; Pham, T.A.; Hoang, V.; Van Le, H.; Le, T.-T.; Nguyen, H.Q.; Bui, G.L. Development of artificial neural networks for prediction of compression coefficient of soft soil. In CIGOS 2019, Innovation for Sustainable Infrastructure; Ha-Minh, C., Dao, D.V., Benboudjema, F., Derrible, S., Huynh, D.V.K., Tang, A.M., Eds.; Springer: Singapore, 2020; pp. 1167-1172.

108. Le, T.-T.; Pham, B.T.; Ly, H.-B.; Shirzadi, A.; Le, L.M. Development of 48-hour precipitation forecasting model using nonlinear autoregressive neural network. In CIGOS 2019, Innovation for Sustainable Infrastructure; Ha-Minh, C., Dao, D.V., Benboudjema, F., Derrible, S., Huynh, D.V.K., Tang, A.M., Eds.; Springer: Singapore, 2020; pp. 1191-1196.

109. Szkuta, B.R.; Sanabria, L.A.; Dillon, T.S. Electricity price short-term forecasting using artificial neural networks. IEEE Trans. Power Syst. 1999, 14, 851-857. [CrossRef]

110. Kumar, S.; Barai, S.V. Neural networks modeling of shear strength of SFRC corbels without stirrups. Appl. Soft Comput. 2010, 10, 135-148. [CrossRef]

111. Darji, M.P.; Dabhi, V.K.; Prajapati, H.B. Rainfall forecasting using neural network: A survey. In Proceedings of the 2015 International Conference on Advances in Computer Engineering and Applications, Ghaziabad, UP, India, 19-20 March 2015; pp. 706-713.

112. Chang, K.-T.; Merghadi, A.; Yunus, A.P.; Pham, B.T.; Dou, J. Evaluating scale effects of topographic variables in landslide susceptibility models using GIS-based machine learning techniques. Sci. Rep. 2019, 9, 1-21. [CrossRef]

113. Pham, B.T.; Nguyen-Thoi, T.; Ly, H.-B.; Nguyen, M.D.; Al-Ansari, N.; Tran, V.-Q.; Le, T.-T. Extreme Learning Machine Based Prediction of Soil Shear Strength: A Sensitivity Analysis Using Monte Carlo Simulations and Feature Backward Elimination. Sustainability 2020, 12, 2339. [CrossRef]

114. Witten, I.H.; Frank, E.; Hall, M.A.; Pal, C.J. Data Mining: Practical Machine Learning Tools and Techniques; Morgan Kaufmann: Burlington, MA, USA, 2016; ISBN 978-0-12-804357-8.

115. Phong, T.V.; Phan, T.T.; Prakash, I.; Singh, S.K.; Shirzadi, A.; Chapi, K.; Ly, H.-B.; Ho, L.S.; Quoc, N.K.; Pham, B.T. Landslide susceptibility modeling using different artificial intelligence methods: A case study at Muong Lay district, Vietnam. Geocarto Int. 2019, 0, 1-24. [CrossRef]

116. Cavaleri, L.; Asteris, P.G.; Psyllaki, P.P.; Douvika, M.G.; Skentou, A.D.; Vaxevanidis, N.M. Prediction of Surface Treatment Effects on the Tribological Performance of Tool Steels Using Artificial Neural Networks. Appl. Sci. 2019, 9, 2788. [CrossRef]

117. Asteris, P.G.; Moropoulou, A.; Skentou, A.D.; Apostolopoulou, M.; Mohebkhah, A.; Cavaleri, L.; Rodrigues, H.; Varum, H. Stochastic Vulnerability Assessment of Masonry Structures: Concepts, Modeling and Restoration Aspects. Appl. Sci. 2019, 9, 243. [CrossRef]

118. Dou, J.; Yunus, A.P.; Merghadi, A.; Shirzadi, A.; Nguyen, H.; Hussain, Y.; Avtar, R.; Chen, Y.; Pham, B.T.; Yamagishi, H. Different sampling strategies for predicting landslide susceptibilities are deemed less consequential with deep learning. Sci. Total Environ. 2020, 720, 137320. [CrossRef]

119. Dodangeh, E.; Shahedi, K.; Pham, B.T.; Solaimani, K. Joint frequency analysis and uncertainty estimation of coupled rainfall-runoff series relying on historical and simulated data. Hydrol. Sci. J. 2020, 65, 455-469. [CrossRef]

120. Asteris, P.G.; Roussis, P.C.; Douvika, M.G. Feed-Forward Neural Network Prediction of the Mechanical Properties of Sandcrete Materials. Sensors 2017, 17, 1344. [CrossRef]

121. Cavaleri, L.; Chatzarakis, G.E.; Trapani, F.D.; Douvika, M.G.; Roinos, K.; Vaxevanidis, N.M.; Asteris, P.G. Modeling of surface roughness in electro-discharge machining using artificial neural networks. Adv. Mater. Res. 2017, 6, 169-184.

122. Plevris, V.; Asteris, P.G. Modeling of masonry failure surface under biaxial compressive stress using Neural Networks. Constr. Build. Mater. 2014, 55, 447-461. [CrossRef]

123. Lourakis, M.I.A. A Brief Description of the Levenberg-Marquardt Algorithm Implemented by levmar. Found. Res. Technol. 2005, 4, 1-6.

124. Asteris, P.G.; Nikoo, M. Artificial bee colony-based neural network for the prediction of the fundamental period of infilled frame structures. Neural Comput. Applic. 2019, 31, 4837-4847. [CrossRef]

125. Donate, J.P.; Li, X.; Sánchez, G.G.; De Miguel, A.S. Time series forecasting by evolving artificial neural networks with genetic algorithms, differential evolution and estimation of distribution algorithm. Neural Comput. Appl. 2011, 22, 11-20. [CrossRef] 
126. Mousavi, S.M.; Mostafavi, E.S.; Jiao, P. Next generation prediction model for daily solar radiation on horizontal surface using a hybrid neural network and simulated annealing method. Energy Convers. Manag. 2017, 153, 671-682. [CrossRef]

127. Nguyen, H.; Drebenstedt, C.; Bui, X.-N.; Bui, D.T. Prediction of blast-induced ground vibration in an open-pit mine by a novel hybrid model based on clustering and artificial neural network. Nat. Resour. Res. 2019, 29, 691-709. [CrossRef]

128. Blanco, A.; Delgado, M.; Pegalajar, M.C. A real-coded genetic algorithm for training recurrent neural networks. Neural Netw. 2001, 14, 93-105. [CrossRef]

129. Irani, R.; Nasimi, R. Evolving neural network using real coded genetic algorithm for permeability estimation of the reservoir. Expert Syst. Appl. 2011, 38, 9862-9866. [CrossRef]

130. Hamacher, K. On stochastic global optimization of one-dimensional functions. Phys. A Stat. Mech. Appl. 2005, 354, 547-557. [CrossRef]

131. Huang, H.; An, H.; Ma, H.; Chen, S. An engineering method for complex structural optimization involving both size and topology design variables. Int. J. Numer. Methods Eng. 2019, 117, 291-315. [CrossRef]

132. Lass, O.; Posch, C.; Scharrer, G.; Volkwein, S. Space mapping techniques for a structural optimization problem governed by the p-Laplace equation. Optim. Methods Softw. 2011, 26, 617-642. [CrossRef]

133. Guilleminot, J.; Le, T.T.; Soize, C. Stochastic framework for modeling the linear apparent behavior of complex materials: Application to random porous materials with interphases. Acta Mech. Sin. 2013, 29, 773-782. [CrossRef]

134. Le, T.T.; Guilleminot, J.; Soize, C. Stochastic continuum modeling of random interphases from atomistic simulations. Application to a polymer nanocomposite. Comput. Methods Appl. Mech. Eng. 2016, 303, 430-449. [CrossRef]

135. Sergeyev, Y.D.; Kvasov, D.E.; Mukhametzhanov, M.S. On the efficiency of nature-inspired metaheuristics in expensive global optimization with limited budget. Sci. Rep. 2018, 8, 1-9. [CrossRef] [PubMed]

136. Arani, K.S.; Zandi, Y.; Pham, B.T.; Mu'azu, M.A.; Katebi, J.; Mohammadhassani, M.; Khalafi, S.; Mohamad, E.T.; Wakil, K.; Khorami, M. Computational optimized finite element modeling of mechanical interaction of concrete with fiber reinforced polymer. Comput. Concr. 2019, 23, 061.

137. Holland, J.H. Adaptation in Natural and Artificial Systems: An Introductory Analysis with Applications to Biology, Control, and Artificial Intelligence, Reprint ed.; A Bradford Book: Cambridge, MA, USA, 1992; ISBN 978-0-262-58111-0.

138. Chang, W.-D. Nonlinear system identification and control using a real-coded genetic algorithm. Appl. Math. Model. 2007, 31, 541-550. [CrossRef]

139. Maulik, U.; Bandyopadhyay, S. Genetic algorithm-based clustering technique. Pattern Recognit. 2000, 33, 1455-1465. [CrossRef]

140. Jahed Armaghani, D.; Asteris, P.G.; Askarian, B.; Hasanipanah, M.; Tarinejad, R.; Huynh, V.V. Examining Hybrid and Single SVM Models with Different Kernels to Predict Rock Brittleness. Sustainability 2020, 12, 2229. [CrossRef]

141. Sedki, A.; Ouazar, D.; El Mazoudi, E. Evolving neural network using real coded genetic algorithm for daily rainfall-runoff forecasting. Expert Syst. Appl. 2009, 36, 4523-4527. [CrossRef]

142. Mohamad, E.T.; Faradonbeh, R.S.; Armaghani, D.J.; Monjezi, M.; Majid, M.Z.A. An optimized ANN model based on genetic algorithm for predicting ripping production. Neural Comput. Appl. 2017, 28, $393-406$. [CrossRef]

143. Gandomi, A.H.; Yang, X.-S.; Alavi, A.H. Mixed variable structural optimization using Firefly Algorithm. Comput. Struct. 2011, 89, 2325-2336. [CrossRef]

144. Srivatsava, P.R.; Mallikarjun, B.; Yang, X.-S. Optimal test sequence generation using firefly algorithm. Swarm Evol. Comput. 2013, 8, 44-53. [CrossRef]

145. Senthilnath, J.; Omkar, S.N.; Mani, V. Clustering using firefly algorithm: Performance study. Swarm Evol. Comput. 2011, 1, 164-171. [CrossRef]

146. Zaman, M.A.; Abdul Matin, M. Nonuniformly Spaced Linear Antenna Array Design Using Firefly Algorithm. Available online: https://www.hindawi.com/journals/ijmst/2012/256759/abs/ (accessed on 15 November 2019).

147. Dao, D.V.; Jaafari, A.; Bayat, M.; Mafi-Gholami, D.; Qi, C.; Moayedi, H.; Phong, T.V.; Ly, H.-B.; Le, T.-T.; Trinh, P.T.; et al. A spatially explicit deep learning neural network model for the prediction of landslide susceptibility. Catena 2020, 188, 104451. [CrossRef] 
148. Pham, B.T.; Le, L.M.; Le, T.-T.; Bui, K.-T.T.; Le, V.M.; Ly, H.-B.; Prakash, I. Development of advanced artificial intelligence models for daily rainfall prediction. Atmos. Res. 2020, 237, 104845. [CrossRef]

149. Pham, B.T.; Van Phong, T.V.; Nguyen-Thoi, T.; Parial, K.; K. Singh, S.; Ly, H.-B.; Nguyen, K.T.; Ho, L.S.; Le, H.V.; Prakash, I. Ensemble modeling of landslide susceptibility using random subspace learner and different decision tree classifiers. Geocarto Int. 2020, 2020, 1-23. [CrossRef]

150. Pham, B.T.; Qi, C.; Ho, L.S.; Nguyen-Thoi, T.; Al-Ansari, N.; Nguyen, M.D.; Nguyen, H.D.; Ly, H.-B.; Le, H.V.; Prakash, I. A Novel Hybrid Soft Computing Model Using Random Forest and Particle Swarm Optimization for Estimation of Undrained Shear Strength of Soil. Sustainability 2020, 12, 2218. [CrossRef]

151. Nguyen, H.Q.; Ly, H.-B.; Tran, V.Q.; Nguyen, T.-A.; Le, T.-T.; Pham, B.T. Optimization of Artificial Intelligence System by Evolutionary Algorithm for Prediction of Axial Capacity of Rectangular Concrete Filled Steel Tubes under Compression. Materials 2020, 13, 1205. [CrossRef]

152. Dao, D.V.; Ly, H.-B.; Vu, H.-L.T.; Le, T.-T.; Pham, B.T. Investigation and Optimization of the C-ANN Structure in Predicting the Compressive Strength of Foamed Concrete. Materials 2020, 13, 1072. [CrossRef]

153. Pham, B.T.; Nguyen, M.D.; Bui, K.-T.T.; Prakash, I.; Chapi, K.; Bui, D.T. A novel artificial intelligence approach based on Multi-layer Perceptron Neural Network and Biogeography-based Optimization for predicting coefficient of consolidation of soil. Catena 2019, 173, 302-311. [CrossRef]

154. Nguyen, V.V.; Pham, B.T.; Vu, B.T.; Prakash, I.; Jha, S.; Shahabi, H.; Shirzadi, A.; Ba, D.N.; Kumar, R.; Chatterjee, J.M. Hybrid machine learning approaches for landslide susceptibility modeling. Forests 2019, 10, 157. [CrossRef]

155. Asteris, P.G.; Kolovos, K.G.; Douvika, M.G.; Roinos, K. Prediction of self-compacting concrete strength using artificial neural networks. Eur. J. Environ. Civil Eng. 2016, 20, s102-s122. [CrossRef]

156. Asteris, P.G.; Kolovos, K.G. Self-compacting concrete strength prediction using surrogate models. Neural Comput. Appl. 2019, 31, 409-424. [CrossRef]

157. Asteris, P.G.; Plevris, V. Anisotropic masonry failure criterion using artificial neural networks. Neural Comput. Appl. 2017, 28, 2207-2229. [CrossRef]

158. Roshni, T.; Jha, M.K.; Deo, R.C.; Vandana, A. Development and Evaluation of Hybrid Artificial Neural Network Architectures for Modeling Spatio-Temporal Groundwater Fluctuations in a Complex Aquifer System. Water Resour. Manag. 2019, 33, 2381-2397. [CrossRef]

159. Armaghani, D.J.; Hajihassani, M.; Sohaei, H.; Mohamad, E.T.; Marto, A.; Motaghedi, H.; Moghaddam, M.R. Neuro-fuzzy technique to predict air-overpressure induced by blasting. Arab. J. Geosci. 2015, 8, 10937-10950. [CrossRef]

160. Sonmez, H.; Gokceoglu, C.; Nefeslioglu, H.A.; Kayabasi, A. Estimation of rock modulus: For intact rocks with an artificial neural network and for rock masses with a new empirical equation. Int. J. Rock Mech. Min. Sci. 2006, 43, 224-235. [CrossRef]

161. Bui, D.-K.; Nguyen, T.; Chou, J.-S.; Nguyen-Xuan, H.; Ngo, T.D. A modified firefly algorithm-artificial neural network expert system for predicting compressive and tensile strength of high-performance concrete. Constr. Build. Mater. 2018, 180, 320-333. [CrossRef]

162. Sulaiman, S.I.; Othman, Z.; Musirin, I.; Abidin, N.S.M.Z. Optimization of an Artificial Neural Network using Firefly Algorithm for modeling AC power from a photovoltaic system. In Proceedings of the 2015 SAI Intelligent Systems Conference (IntelliSys), London, UK, 10-11 November 2015; pp. 591-594.

163. Qi, C.; Tang, X.; Dong, X.; Chen, Q.; Fourie, A.; Liu, E. Towards Intelligent Mining for Backfill: A genetic programming-based method for strength forecasting of cemented paste backfill. Miner. Eng. 2019, 133, 69-79. [CrossRef]

164. Slater, E.; Moni, M.; Alam, M.S. Predicting the shear strength of steel fiber reinforced concrete beams. Constr. Build. Mater. 2012, 26, 423-436. [CrossRef]

165. Kara, I.F. Empirical modeling of shear strength of steel fiber reinforced concrete beams by gene expression programming. Neural Comput. Appl. 2013, 23, 823-834. [CrossRef]

166. Tian, J.; Qi, C.; Sun, Y.; Yaseen, Z.M.; Pham, B.T. Permeability prediction of porous media using a combination of computational fluid dynamics and hybrid machine learning methods. Eng. Comput. 2020, 1-17. [CrossRef]

167. Rahmani, A.; MirHassani, S.A. A hybrid Firefly-Genetic Algorithm for the capacitated facility location problem. Inf. Sci. 2014, 283, 70-78. [CrossRef]

168. Thakur, M.; Kumar, A. Optimal coordination of directional over current relays using a modified real coded genetic algorithm: A comparative study. Int. J. Electr. Power Energy Syst. 2016, 82, 484-495. [CrossRef] 
169. Haghrah, A.; Nazari-Heris, M.; Mohammadi-Ivatloo, B. Solving combined heat and power economic dispatch problem using real coded genetic algorithm with improved Mühlenbein mutation. Appl. Therm. Eng. 2016, 99, 465-475. [CrossRef]

170. Khuntia, M.; Stojadinovic, B.; Goel, S.C. Shear strength of normal and high-strength fiber reinforced concrete beams without stirrups. ACI Struct. J. 1999, 96, 282-289.

171. Sarveghadi, M.; Gandomi, A.H.; Bolandi, H.; Alavi, A.H. Development of prediction models for shear strength of SFRCB using a machine learning approach. Neural Comput. Appl. 2015, 31, 2085-2094. [CrossRef]

172. Yakoub, H.E. Shear stress prediction: Steel fiber-reinforced concrete beams without stirrups. ACI Struct. J. 2011, 108, 304-314.

173. Lantsoght, E.O.L. Database of Shear Experiments on Steel Fiber Reinforced Concrete Beams without Stirrups. Materials 2019, 12, 917. [CrossRef]

(C) 2020 by the authors. Licensee MDPI, Basel, Switzerland. This article is an open access article distributed under the terms and conditions of the Creative Commons Attribution (CC BY) license (http://creativecommons.org/licenses/by/4.0/). 